ANÁLISE DO PERFIL DOS POTENCIAIS DOADORES DE ÓRGÃOS PEDIÁTRICOS NO DISTRITO FEDERAL, DE 2013 A 2016 


\section{BRUNA ROLIM PEIXOTO DA SILVA MARCOS PAULO GONÇALVES CARLOS}

\section{ANÁLISE DO PERFIL DOS POTENCIAIS DOADORES DE ÓRGÃOS PEDIÁTRICOS NO DISTRITO FEDERAL, DE 2013 A 2016}

Relatório final de pesquisa de Iniciação Científica apresentado à Assessoria de Pós-Graduação e Pesquisa pela Faculdade de Ciências da Educação e da Saúde - FACES.

Orientação: Andréa Lopes Ramires Kairala. 


\section{AGRADECIMENTOS}

A Deus, por nos aproximar de pessoas fantásticas e singulares, por sempre nos proporcionar oportunidade de crescer em todas as esferas possíveis e pela vida com a qual fomos premiados.

À nossa professora orientadora, Andréa Lopes Ramires Kairala, por todo o suporte, incentivo e paciência ao longo desses meses de trabalho.

Aos servidores da Captação e Distribuição de Órgãos do Distrito Federal (CNCDO/DF) e Organização de Procura de Órgãos e Tecidos do Distrito Federal $(\mathrm{OPO} / \mathrm{DF})$, especialmente à Dra Daniela Ferreira Salomão e às enfermeiras Viviane Marçal da Silva e Camila Vieira Hirata, pela autorização da pesquisa e por todo apoio fornecido.

Ao UniCEUB, pela oportunidade de participarmos do 15o Programa de Iniciação Científica, tão importante para o nosso enriquecimento acadêmico e profissional e pelos subsídios necessários para a realização dessa pesquisa. 


\title{
ANÁLISE DO PERFIL DOS POTENCIAIS DOADORES DE ÓRGÃOS PEDIÁTRICOS NO DISTRITO FEDERAL, DE 2013 A 2016
}

\author{
Bruna Rolim Peixoto da Silva - UniCEUB, PIC Institucional, aluna bolsista \\ muna_rpds@hotmail.com
}
Marcos Paulo Gonçalves Carlos - UniCEUB, PIC institucional, aluno voluntário mpcg14@gmail.com

Andréa Lopes Ramires Kairala - UniCEUB, professora orientadora kairalak@uol.com.br

Essa pesquisa visa demonstrar um panorama geral dos transplantes post mortem de órgãos pediátricos, no Distrito Federal (DF), com o intuito de identificar em que esferas as ações de saúde e as estratégias de conscientização da população e dos profissionais de saúde são mais necessárias, para que se aumente a quantidade de doadores efetivos e para que se estimule a criação de uma cultura de doação, superando os mitos e preconceitos a respeito do assunto. $O$ objetivo do projeto foi coletar os dados epidemiológicos dos potenciais doadores de órgãos pediátricos, que sofreram morte encefálica (ME), de 0 a 18 anos, no DF, dos últimos 4 anos. Foi um estudo transversal/ retrospectivo, onde foram analisados prontuários de crianças e adolescentes $(\mathrm{N}=146)$ em ME acompanhados pela equipe da Central de Notificação, Captação e Distribuição de Órgãos (CNCDO) do DF, entre janeiro de 2013 e dezembro de 2016. Da população analisada $(N=146)$, apenas $34,2 \%(N=50)$ efetivaram a doação de órgãos. Entre o período de tempo analisado, observou-se uma constante no número de potenciais doadores e porcentagem de doadores efetivos ( $\mathrm{N}=40 / 32,5 \%, \mathrm{~N}=38 / 28,9 \%, \mathrm{~N}=35 / 42,8 \%$ e $\mathrm{N}=33 / 33,3 \%)$. Verificou-se ainda predominância de adolescentes (51,4\%), sexo masculino $(67,8 \%)$ e cor parda $(57,5 \%)$. No que se refere a faixa etária, foi observada uma semelhança de porcentagem entre escolares $(18,5 \%)$ e lactentes (17,1\%); apenas $12,3 \%$ de préescolares e $0,7 \%(\mathrm{~N}=1)$ recém-nascidos. Entre os motivos de internação e óbito verificou-se a predominância de causas externas $(41,1 \%)$, dessas, $21,9 \%$ por atropelamento; $18,5 \%$ perfuração por arma de fogo e 0,7\% enforcamento; e 13,7\% por tumores cerebrais. Primeiro atendimento de $84,9 \%$ foi realizado na rede pública. Ao analisar onde o protocolo de ME foi iniciado, percebe-se aumento de indivíduos na rede pública $(93,8 \%)$ sugerindo-se que os pacientes com agravamento da situação de saúde, foram transferidos para hospitais especializados da rede pública do DF. Quanto a notificação, verifica-se que $25,4 \%$ dos casos declarados foram por busca ativa pela equipe (OPO-DF) sendo o restante por notificação da equipe assistencial (68,5\%); em 6,1\% dos prontuários não havia informação sobre esse dado. Os motivos mais frequentes para não doação decorrem de parada cardiorrespiratória antes do encerramento do protocolo (36\%), recusa dos familiares (25\%) e neoplasia maligna (18\%). Quanto aos tipos de órgãos, em média são doados 3 por paciente; predominam rins (34\%) e fígado (25,7\%). A maioria das retiradas (78\%) ocorreram no Instituto de Cardiologia do DF. É necessário, como aponta a Associação Brasileira de Transplantes de Órgãos, planejar estratégias de 
incremento no transplante pediátrico no Brasil, como educação para a população. Adolescentes pardos do sexo masculino são mais vulneráveis à morte encefálica por causas externas, em sua maioria evitáveis. É preciso uma maior atenção à situação de segurança dessa população pelas autoridades governamentais. Percebe-se ainda que existe um aumento da conscientização das equipes de saúde em notificar a CNCDO/DF sobre a suspeita de ME e isso tem relação com um maior preparo e eficiência das equipes assistenciais. Mas esses números podem aumentar, principalmente diante da fila de crianças que ainda esperam o transplante para sobreviver.

Palavras-Chave: Transplante de Órgãos. Pediatria. Morte encefálica. 
1 INTRODUÇÃO

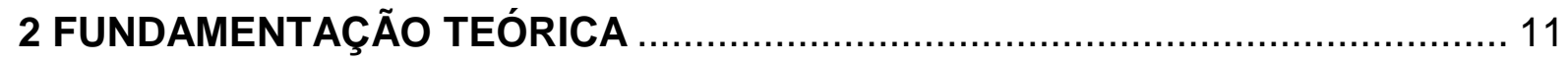

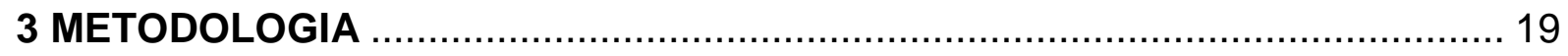

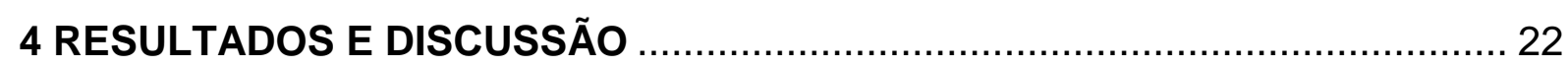

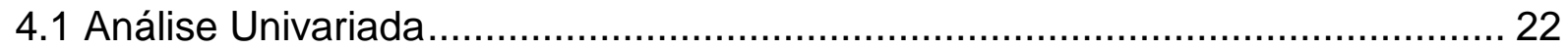

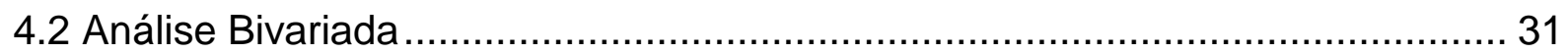

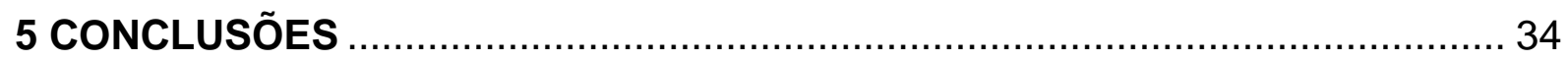

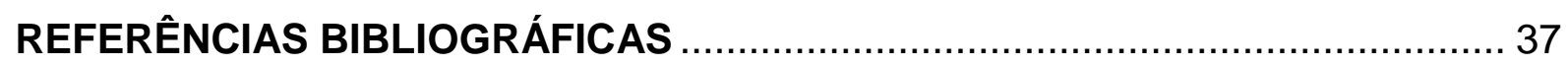

APÊNDICE A - Ficha de Coleta de Dados .................................................... 42

APÊNDICE B - Dispensa de Termo de Consentimento Livre e Esclarecido..... 43

ANEXO A - Protocolo de Morte Encefálica, de acordo com o CFM ................... 46

ANEXO B - Parecer do Comitê de Ética do UniCEUB ........................................ 47

ANEXO C - Parecer do Comitê de Ética da FEPECS/SES/DF ........................... 51 


\section{SIGLAS E ABREVIATURAS}

ABTO - Associação Brasileira de Transplante de Órgãos

CFM - Conselho Federal de Medicina

CIHDOTT - Comissão Intra-Hospitalar de Doação de Órgãos e Tecidos para

Transplantes

CNCDO - Central de Notificação, Captação e Distribuição de Órgãos

$\mathrm{CNH}$ - Carteira Nacional de Habilitação

DF - Distrito Federal

ECGI - Escala de Coma de Glasgow

FEPECS - Fundação de Ensino e Pesquisa em Ciências da Saúde

HBDF - Hospital de Base do Distrito Federal

HIV - Vírus da Imunodeficiência Humana Adquirida

HTLV I e II - Human T Lymphotropic Virus Type I and II (vírus T linfotrópico humano tipos I e II)

ME - Morte Encefálica

OPO - Organização de Procura de Órgãos

PCR - Parada Cardiorrespiratória

PS - Pronto-Socorro

$R G$ - Registro Geral

SES - Secretaria de Estado da Saúde

SNT - Sistema Nacional de Transplantes

TCE - Traumatismo Cranioencefálico

UniCEUB - Centro Universitário de Brasília

UTI - Unidade de Terapia Intensiva 


\section{INTRODUÇÃO}

O transplante de órgão ou de tecido é uma opção de tratamento que consiste na substituição de um órgão ou de um tecido, de pessoas de qualquer idade, que apresentem doença crônica de caráter irreversível e em estágio final, por outro órgão sadio, de um doador vivo ou falecido. $O$ procedimento visa a melhora da qualidade de vida ou mesmo a cura dessas pessoas doentes (MENDES et al, 2012).

Essa pesquisa visa demonstrar um panorama geral dos transplantes post mortem de órgãos pediátricos, no Distrito Federal (DF), com o intuito de identificar em que esferas as ações de saúde e as estratégias de conscientização da população e dos profissionais de saúde são mais necessárias, para que se aumente a quantidade de doadores efetivos e para que se estimule a criação de uma cultura de doação, superando os mitos e preconceitos a respeito do assunto (MORAIS T.; MORAIS M., 2012).

A doação e alocação de órgãos é um processo complexo, que depende do compromisso de vários profissionais e de sua atuação em sequência: no diagnóstico de morte encefálica, na identificação dos potenciais doadores até a efetivação dos transplantes e seu acompanhamento ambulatorial. Esse processo possibilita transformar um potencial doador em doador efetivo de órgãos e/ou tecidos, tendo por finalidade o transplante (PARANÁ, 2014; ABTO, 2015). A definição de morte foi revista e modificada a partir do advento de tecnologia suficiente para manter as funções vitais, mesmo na ausência de atividade cerebral (JOFFE; ANTON, 2006).

A morte encefálica (ME), no Brasil foi definida como a constatação irremediável e irreversível da lesão nervosa, mediante comprovação de critérios clínicos e tecnológicos. O diagnóstico de ME é obrigatório e a notificação é compulsória para a Central de Notificação, Captação e Distribuição de Órgãos (CNCDO) a qual estiver vinculada a unidade hospitalar onde o indivíduo se encontrava internado. Para tanto, deve ser aberto o protocolo para todos os pacientes com suspeita de ME, independentemente da possibilidade de doação ou não de órgãos e/ou tecidos (CONSELHO FEDERAL DE MEDICINA, 1997).

As causas da não doação de órgãos podem ser variadas: recusa familiar; demora na finalização do protocolo de morte encefálica e consequente parada 
cardiorrespiratória antes do encerramento do protocolo; contraindicações clínicas da doação (doenças infectocontagiosas transmissíveis); entre outras. É importante saber a causa da não-doação para que haja uma tentativa de diminuição do fenômeno (SILVA et al, 2002).

Muitas pessoas ainda possuem muitas dúvidas e preconceitos a respeito da doação de órgãos; a falta de esclarecimento, o noticiário sensacionalista sobre tráfico de órgãos, a ausência de programas permanentes voltados para a conscientização da população e a falta de incentivo à captação de órgãos aumentam ainda mais as incertezas sobre o processo. A própria dificuldade em compreender o conceito da morte encefálica contribui para a negação. É difícil acreditar que o cérebro realmente está morto, se o coração está batendo e os outros órgãos estão funcionando. O esclarecimento da população a respeito do assunto seria, portanto, um importante fator de aumento das doações de órgãos (MORAES; GALLANI; MENEGHIN, 2006).

O Brasil tem um programa de transplantes bem consolidado: com mais de 190 milhões de habitantes, a fila para transplantes de córneas está quase zerada, e atende-se cerca de $40 \%$ da necessidade anual para transplantes renais e $30 \%$ para transplantes hepáticos. No entanto, ainda é significativa a mortalidade na fila de espera, principalmente para transplante de fígado e de coração. Quem aguarda por um rim sobrevive mais tempo na fila, em decorrência da hemodiálise (ABTO, 2015; MARINHO, 2006).

Segundo o Registro Brasileiro de Transplantes (2016, p. 6) da Associação Brasileira de Transplantes de Órgãos, alguns pontos importantes devem ser destacados: além de ter um programa de transplantes bem consolidado, existe o apoio do setor público aos programas e está havendo uma melhora progressiva nos resultados dos transplantes. Entretanto, recentemente, tem havido um crescimento insuficiente nas doações, elevados índices de recusa familiar à doação, importantes disparidades entre estados e regiões, limitações financeiras de alguns programas e baixo índice de notificações de morte encefálica.

Existe uma escassez mundial crescente de órgãos e tecidos para transplante, especialmente para crianças, que frequentemente precisam de órgãos e tecidos apropriados para seu tamanho e tem um risco elevado de morrer, enquanto na lista 
de espera. Além disso, os dados empíricos sobre a obtenção de doadores pediátricos são escassos (SIEBELINK et al, 2012a; WORKMAN et al, 2013). Ao longo dos últimos 8 anos, 283 crianças nos países que participam da "Eurotransplant" morreram enquanto esperavam na lista de espera. Ademais, o número de doadores pediátricos está diminuindo. No Brasil e na China, a situação é semelhante (HUANG et al, 2013; SIEBELINK et al, 2012b; ABTO, 2015).

Estudos de Siebelink et al (2012a) e Rodrigues et al (2013) apontam que os esforços para resolver a escassez de órgãos e tecidos para transplantes em crianças deve concentrar-se na identificação de potenciais doadores e as razões para os pais não concordarem com a doação.

Os dados epidemiológicos de transplantes de órgãos sólidos pediátricos (coração, pulmão, rim, fígado), no Brasil, apontam uma variação no número de transplantes pediátricos: em 2012, houve no total 584 transplantes; em 2013, 554; em 2014, houve no total 578; em 2015, 532 e em 2016, 527 transplantes pediátricos. É possível perceber assim uma redução de transplantes quando comparamos o ano 2015 e de 2016 com os anos 2012, 2013 e 2014. Apenas no Registro Brasileiro de Transplantes 2015 passa-se a ter dados iniciais da lista de espera de transplante pediátrico e da mortalidade dos pacientes, enquanto estão na fila. Em dezembro de 2015, havia 379 crianças ativas em lista de rim, 102 de fígado, 49 de coração e 15 de pulmão. (ABTO, 2012, 2013, 2014b, 2015, 2016).

A população pediátrica no Brasil está em torno de 53 milhões. No ano de 2016, 705 crianças ingressaram em lista para realizar transplantes de órgãos sólidos no Brasil. Faleceram na lista de espera 78 crianças. Comparado ao ano 2015, em número absolutos, houve redução no número de transplantes de órgãos sólidos em crianças no Brasil em 2016: 527, contra 532. O que chama a atenção nos dados de 2016 é que foram transplantadas 74\% das crianças que ingressaram em lista. Mais uma vez, há necessidade de trabalhar na facilitação para que as crianças com falência de órgãos cheguem aos centros de transplante e, sempre, na educação para a doação de órgãos. (ABTO, 2015, 2016).

No Distrito Federal, durante o ano de 2015, ingressaram na lista de espera de transplantes pediátricos 50 crianças; 4 delas (8\%) morreram nessa fila de espera, sendo 3 óbitos de crianças que esperavam por um transplante de coração e 1 óbito de criança que esperava por um transplante de fígado. Já em 2016, ingressaram na 
lista de espera de transplantes pediátricos 17 crianças; 2 (11,76\%) delas morreram nessa fila de espera, ambas esperando um transplante de coração (ABTO, 2015 p. 23; ABTO, 2016 p. 23).

A dificuldade de obtenção de um órgão possui diversas variáveis além do peso do receptor. Entre eles o tipo sanguíneo, a idade, a distribuição geográfica, 0 conhecimento sobre 0 assunto, entre outras. A escassez de doadores, principalmente bebês e crianças, estaciona o número de transplantes realizados no país e contribui para o aumento na taxa de mortalidade dos pacientes em espera (INCOR, 2015).

A importância desse trabalho advém, portanto, do fato de que houve redução no número de transplantes pediátricos nos anos de 2015 e de 2016, e da possibilidade de análise de fatores do paciente e de causas que colaboraram com essa diminuição.

O objetivo geral desse projeto foi coletar os dados epidemiológicos dos potenciais doadores de órgãos pediátricos, que sofreram morte encefálica, de 0 a 18 anos, no Distrito Federal (DF), de janeiro de 2013 a dezembro de 2016, buscando demonstrar as principais causas da não-captação de órgãos, bem como o número total de doadores pediátricos efetivos e não-efetivos, o número total de transplantes realizados, e outras variáveis epidemiológicas, visando a proposta de educação e conscientização da população sobre a doação de órgãos, para que assim o número de doações aumente.

Os objetivos específicos foram: verificar o perfil epidemiológico de todos os potenciais doadores de órgãos pediátricos, que sofreram morte encefálica, no DF; comparar os perfis dos potenciais doadores pediátricos efetivos e não-efetivos, analisando a causa de morte encefálica, a causa de internação de cada um dos pacientes e o desfecho do caso (doação ou não-doação); demonstrar variáveis que se relacionem estatisticamente com a doação de órgãos e que facilitem assim o processo. 


\section{FUNDAMENTAÇÃO TEÓRICA}

A história dos transplantes de órgãos é antiga, e há relatos de que um cirurgião chinês, Pien Chiao, realizou, com êxito, a troca de órgãos entre dois irmãos, cerca de 300 a.C. Nos séculos XV e XVI, foram descritas as primeiras tentativas de utilizar tecidos procedentes de pessoas e animais, porém, as operações terminaram fracassando, pois a extração era feita de forma primitiva, sem levar em consideração as infecções (LEITE, 2000).

O cirurgião francês Ambrósio Paré (1517-1590), um dos precursores das técnicas cirúrgicas utilizadas nos transplantes, foi chamado "o pai da cirurgia moderna". Teve como pico, em sua carreira, a descoberta da ligação das artérias, que ele empregou nas amputações, segundo um método seu, como substituto da cauterização. Já o cirurgião inglês John Hunter (1728 - 1793) foi o primeiro a usar a palavra "transplante" (LEITE, 2000).

Em 1902, Ullman e Unger realizaram o primeiro transplante renal autólogo em um cão, ou seja, retiraram o rim do próprio animal. O primeiro uso de um rim humano para o transplante ocorreu em 1936, quando Yu Yu Voronoy, na Ucrânia, realizou o primeiro de uma série de seis transplantes para tratar pacientes morrendo de insuficiência renal aguda secundária a intoxicação por mercúrio, ingerida por suas vítimas na tentativa de suicídio, mas todos os transplantes falharam. Foi a partir da década de 50 que o transplante renal se tornou viável. (WATSON; DARK, 2012).

O primeiro transplante registrado no Brasil foi o de córneas, em 1954. Segundo Ferreira (1997), esse tipo de transplante é um procedimento seguro e por isso, aumentou durante os últimos anos, o que fez com que, cada vez mais, fossem estudados e estabelecidos os critérios de avaliação do tecido do doador.

O sucesso no transplante de fígado levou mais tempo que o transplante renal. O receptor geralmente é muito mais doente do que o receptor de transplante renal, a operação é mais difícil e geralmente é realizada na presença de uma coagulopatia significativa. As tentativas iniciais de transplante de fígado, em 1963, por Starzl, em Denver, não tiveram êxito, mas após uma mudança para Pittsburgh, em 1967, seus resultados melhoraram. Depois de muitos avanços, o transplante hepático foi aceito 
como uma opção terapêutica, em 1983, quando a sobrevida dos pacientes saltou de 30\% para 90\% (WATSON; DARK, 2012).

O primeiro transplante de pulmão foi realizado por Hardy, em 1963. Embora o paciente tenha morrido de insuficiência renal após 3 semanas, o caso é notável porque o pulmão foi doado após a morte circulatória e a função precoce do pulmão foi excelente (HARDY et al, 1963). Ferreira (1997) relata que o pico do transplante pulmonar no Brasil se deu em Porto Alegre, em 1989, onde foi realizado o primeiro transplante pulmonar na América do Sul, colocando o Brasil no contexto mundial dos transplantes pulmonares.

O primeiro transplante cardíaco em humanos foi realizado em 1967: o cirurgião sul-africano Christian Barnard o realizaria, ao colocar o coração de Denise Duval no peito de Louis Washkansky, no Hospital Grotte Schur. Menos de um ano depois, e após 17 experiências semelhantes no mundo todo, um ex-aluno brasileiro de Barnard realizaria o primeiro transplante de coração no Brasil, no Hospital das Clínicas de São Paulo. O médico paulista Euryclides de Jesus Zerbini, em 26 de maio de 1968, ganharia as manchetes dos jornais e revistas ao colocar o coração de um jovem morto em um acidente no peito de João Ferreira da Cunha, um camponês conhecido como "João Boiadeiro". A cirurgia foi celebrada como um marco sem par e Zerbini seria entronizado como herói, a despeito de Cunha ter sobrevivido por apenas 18 dias depois do transplante. Naquela época, ainda não se sabia contornar o grande entrave dos transplantes de órgãos, a rejeição (FERREIRA, 1997; MANGINI et al, 2015; MARTINELLI, 2013).

No Brasil são realizados cerca de 19 mil transplantes de múltiplos órgãos por ano, número ainda muito inferior ao de 70 mil pessoas que estão em listas de espera por um transplante. Dessa forma, muitos morrerão antes mesmo de terem a chance de uma nova vida (CAMARGO, 2009).

As atividades de transplantes no Brasil só foram regularizadas de fato em 1997, com a Lei n. 9.434/1997 e o Decreto n. 2.268/1997, que regulamentaram as atividades de transplantes no Brasil e criaram o Sistema Nacional de Transplantes (SNT). Com a Lei n. 9.434/1997, a doação no Brasil passou a ser do tipo presumida (todos eram doadores a não ser que expressassem vontade contrária em documento de identificação - RG ou carteira nacional de habilitação - $\mathrm{CNH}$ ), em vez de consentida. No entanto, essa medida causou certo desconforto na sociedade e, em 2001, a doação voltou a ser consentida, ou seja, só é realizada com o 
consentimento familiar por escrito de parentes de primeiro ou segundo graus, na linha reta e colateral, ou de cônjuge. Além disso, ainda conforme a legislação, a aquisição de partes do corpo humano, para fins terapêuticos ou humanitários, poderá ser feita apenas pela doação gratuita, em vida ou post mortem (BRASIL, 1997a; BRASIL, 1997b; BONFADINI et al, 2014).

No Brasil todo paciente que precisa de transplante é inscrito na Lista Única de Receptores do Sistema Nacional de Transplantes do Ministério da Saúde (cuja ordem é seguida com rigor, sob supervisão do Ministério Público), por uma equipe responsável pelo procedimento do transplante. O cadastro é separado por órgãos, tipos sanguíneos e outras especificações técnicas. A lista única tem ordem cronológica de inscrição, no entanto os receptores são selecionados em função não apenas do tempo, mas também da gravidade e da compatibilidade sanguínea e genética do doador (MINISTÉRIO DA SAÚDE, 2009).

A coordenação logística e a distribuição de órgãos e tecidos para transplantes são de responsabilidade da Central de Notificação, Captação e Distribuição de Órgãos (CNCDO); e realizadas em âmbito nacional pela Central Nacional de Transplantes (CNT), e em âmbito estadual pelas Secretarias de Saúde dos Estados/ Secretaria Estadual de Transplantes. As Organizações de Procura de Órgãos (OPO) fazem parte desse processo de coordenação, e sua criação depende das CNCDO. Atuam de maneira regionalizada em parceria com as Comissões Intra-Hospitalares de Doação de Órgãos e Tecidos para Transplante (CIHDOTT), proporcionando educação continuada na área da doação de órgãos; auxílio aos hospitais para a identificação dos potencias doadores; e auxílio no processo de diagnóstico de morte encefálica (ME), bem como na conclusão do processo de doação e transplante (MINISTÉRIO DA SAÚDE, 2009).

As CIHDOTT atuam com a finalidade de melhorar a identificação e a manutenção de potenciais doadores; também têm caráter educativo; e se articulam com as OPO, que, por sua vez, se articulam com as CNCDO durante todo o processo de doação e transplante (MINISTÉRIO DA SAÚDE, 2009).

O processo tem seu início na identificação de um potencial doador de órgãos e/ou tecidos na unidade de terapia intensiva (UTI) ou no pronto-socorro (PS). Geralmente, os possíveis doadores são pacientes internados por causas neurológicas (acidente vascular encefálico, traumatismo craniano, tumores cerebrais, meningites, encefalopatia anóxica, etc.), que mantêm grau 3 na escala de 
coma de Glasgow (ECGI = 3), sem resposta a estímulos (MOURA; SILVA, 2014; SOUZA; LIRA; MOLA; 2015).

A partir da notificação e da abertura do protocolo de ME, deve-se comunicar a família sobre a possibilidade da doação. Todo paciente que tenha seu protocolo de morte encefálica finalizado e a doação autorizada pela família é um potencial doador de órgãos. No entanto, existem condições que contraindicam absolutamente a doação, como: soropositividade para HIV, e para HTLV I e II; tuberculose em atividade; neoplasias malignas; sepse ativa e refratária. Para os pacientes que não possuírem contraindicações, ações multiprofissionais devem ser empregadas para a manutenção hemodinâmica a fim de promover perfusão sanguínea adequada aos órgãos e tecidos, visando sua preservação até o momento da doação, lembrando sempre que a família deve ser orientada e apoiada durante todo o processo (FREIRE et al, 2013; MOURA; SILVA, 2014).

Para Joynt (1984) e Workman et al (2013), a morte encefálica é definida como a cessação completa da circulação sanguínea e das funções metabólicas e elétricas do córtex cerebral, do telencéfalo e do tronco cerebral. Para o diagnóstico de ME, o paciente deve atender aos critérios clínicos e exames complementares para morte encefálica (ME) estabelecidos na Resolução n. 1.480/1997 do Conselho Federal de Medicina. De acordo com esta, é preciso que as avaliações clínicas e os exames complementares comprovem a falência encefálica, e a inatividade cerebral de forma inequívoca. Além disso, intervalos devem ser seguidos para a realização das avaliações de confirmação da ME, segundo a faixa etária; e ainda, é necessário um termo de declaração de $\mathrm{ME}$, documento no qual deve ser registrada a realização do diagnóstico (anexo A).

Encerrado o protocolo de ME, o médico responsável pelo paciente no hospital comunica o óbito à família, e um profissional capacitado - da CNCDO, OPO ou Comissão Intra-Hospitalar de Doação de órgãos e Tecidos para Transplantes (CIHDOTT) - realiza a avaliação de viabilidade do potencial doador, a fim de afastar todas as contraindicações absolutas para a doação de órgãos. Após essa análise, esse profissional prossegue com a entrevista familiar, informando a possibilidade da doação de órgãos e tecidos. A validação do potencial doador ocorre somente após a família entender claramente o conceito de morte do seu ente querido. Um único potencial doador em boas condições poderá beneficiar, por meio de transplantes, mais de 10 pacientes. Mesmo que um potencial doador se torne um doador efetivo, 
não significa que todos os órgãos poderão ser aproveitados. Para isso é necessário garantir uma adequada preservação destes órgãos até a extração e efetiva doação (PEREIRA; FERNANDES; SOLER, 2009).

Depois de obter o consentimento familiar, a OPO articula-se com o hospital e a CNCDO, a fim de organizar a captação dos órgãos e/ou tecidos a ser doados. São coletados exames e transmitidas informações clínicas, laboratoriais e antropométricas referentes ao paciente à CNCDO, para que esta realize a distribuição dos órgãos às equipes de transplante, conforme a ordem do Cadastro Técnico Único (MOURA; SILVA, 2014).

A retirada de órgãos e tecidos não necessariamente é feita no hospital notificador. O local de primeiro atendimento, o hospital notificador da ME (que realizou a abertura e o fechamento do protocolo) e o hospital de retirada (captador/transplantador) podem ser locais diferentes. Alguns fatores podem limitar a retirada dos órgãos no hospital notificador, como a capacidade de realização de exames prévios à doação, seja por falta de equipamento, seja por falta de profissional especializado. Como exemplo, para o transplante cardíaco, é preciso, em muitos casos, realizar um ecocardiograma e uma cineangiocoronariografia no doador. Quando o hospital notificador não pode realizar todo os exames necessários, ou existem outros fatores limitantes, um hospital mais capacitado deve fazer a retirada. Ao término da cirurgia, o corpo do paciente é entregue condignamente recomposto, à família, à qual são dadas as devidas condolências (MANGINI et al, 2015; ROZA et al, 2006.)

No caso de negativa familiar, o profissional médico está autorizado a suspender os procedimentos terapêuticos empregados ao paciente, já que fora constatado seu óbito, uma vez que as informações tenham sido adequadamente fornecidas e compreendidas pela família, constando registro em prontuário. Entretanto, o CFM recomenda a participação da família na decisão (CONSELHO FEDERAL DE MEDICINA, 2007).

A sequência de atuação das equipes na cirurgia de extração de múltiplos órgãos é definida de acordo com a isquemia do órgão: respectivamente coração (4 horas), pulmões (4 a 6 horas), fígado (12 horas), pâncreas (até 20 horas), intestino (6 a 8 horas), rins (até 36 horas), vasos, córnea, pele e outros tecidos. (GARCIA, C.; PEREIRA, J.; GARCIA, V., 2015). 
Os tempos de isquemia (fria, quente e total) é o delta $T$ entre a parada circulatória do doador até a reperfusão do enxerto no receptor. São divididos em: tempo de isquemia fria: hora do clampeamento da artéria no doador até a retirada do enxerto do gelo; tempo de isquemia quente: retirada do enxerto do gelo até a reperfusão do órgão (REQUIÃO-MOURA et al, 2015).

Um dos primeiros sucessos nos transplantes pediátricos foi o transplante cardíaco. Em 1984, o recém-nascido James Lovette nasceu com uma condição cardíaca muito grave. Naquele momento, apenas alguns transplantes cardíacos tinham sido realizados em crianças, e as taxas de sobrevivência não foram encorajadoras. Em 1967, três dias depois de o cirurgião sul-africano Dr. Christian Barnard ter realizado o primeiro transplante de coração adulto, o Dr. Adrian Kantrowitz realizou o primeiro transplante de coração pediátrico em um bebê de Nova York, que viveu apenas 6 horas. Em 1984, o cirurgião londrino, Dr. Magdi Yacoub, realizou um transplante cardíaco em um bebê de 10 dias de idade, e essa criança sobreviveu 18 dias. Em suma, as chances não eram favoráveis a James. Com ninguém para recorrer, seus pais o levaram a Columbia na cidade de Nova York e pediram para o Dr. Eric Rose que assumisse seu caso. O Dr. Rose e sua equipe estavam menos preocupados com a cirurgia em si e muito mais preocupados com a resposta de James ao novo órgão. A operação ocorreu em 9 de junho de 1984. Depois, a equipe improvisou o melhor que puderam, titulando doses de ciclosporina para evitar que seu corpo rejeitasse o coração. E funcionou. (COLUMBIA, 2015).

Os cientistas, por muitos anos, tiveram a ideia de substituir o órgão doente pelo saudável de um doador. Inicialmente o que ocorria era a chamada rejeição, que é o processo do sistema imunológico onde as células brancas do sangue atacam e tentam destruir o tecido desconhecido. Mas, nos anos 60 os médicos descobriram como realizar transplantes entre pessoas sem parentesco, através da supressão da reação imunológica, suficiente para permitir o transplante do enxerto, sendo ao mesmo tempo adequadamente específico, de modo que outras respostas imunes de proteção permanecessem intactas. O primeiro agente de sucesso foi a azatioprina, um análogo de purina e um derivado menos tóxico de 6-mercaptopurina que, por sua vez, mostrou ser efetivo para permitir uma longa sobrevivência de transplantes de rim para cães (WATSON; DARK, 2012). 
Mas a era imunossupressora moderna veio mesmo com a descoberta dos efeitos imunossupressores da ciclosporina em meados da década de 1970. Inicialmente desenvolvido como um fármaco antifúngico, a ciclosporina foi tóxica em roedores, embora curiosamente, foi observado que permitia enxertos de pele entre eles. Dois anos depois, a droga passou por seus primeiros ensaios clínicos em Cambridge e demonstrou ser um imunossupressor poderoso. A ciclosporina melhorou dramaticamente os resultados do transplante renal e também forneceu imunossupressão suficiente para permitir o sucesso do transplante de fígado, pâncreas, coração e pulmão (WATSON; DARK, 2012).

Muitas famílias têm o desejo de doar órgãos para ajudar a salvar a vida de outras pessoas, porém estas têm dúvidas a respeito do que é a morte encefálica e o que ocorre após a doação. Elas enfrentam uma série de dilemas éticos na hora de decidir o que fazer com o ente querido recém-perdido. Além disso, esse processo representa uma situação traumática e a falta de atenção e comunicação desestimula as famílias dos potenciais doadores (MACEDO; OLIVEIRA, 2013).

O suporte social influencia fortemente na redução das incertezas. Os significados e respostas vão surgindo à medida que os familiares interagem com os profissionais de saúde, amigos, membros da família e com o meio. A família interpreta a situação e busca nas interações sociais uma confirmação para sua interpretação. Ela adquire conhecimento sobre o ambiente, as pessoas e a situação e, assim, associa novos saberes, reduzindo suas inseguranças até se dar conta da complexidade e gravidade do caso (BOUSSO, 2008; MARTÍN-ESCOBAR, 2012). É também importante que haja nesse processo empatia profissional e uma equipe de saúde bem confiável; além disso, a boa comunicação influencia na vontade da doação de forma positiva (SIEBELINK et al, 2012b).

O médico da atenção primária participa do cuidado integral da família e, por isso, está envolvido no apoio e acompanhamento da família do doador. Além do apoio da família, a equipe do centro médico local também devem receber treinamento para lidar com a morte de uma criança, incluindo a confidencialidade e as questões religiosas, culturais e éticas (AMERICAN ACADEMY OF PEDIATRICS, 2002).

Como a morte de uma criança muitas vezes não está prevista, muitas famílias não têm considerado a possibilidade de doação de órgãos. Pediatras, grupos de defesa das crianças, e instituições que cuidam de crianças precisam aumentar a 
consciência da necessidade de doação com o mesmo zelo com que as doações de sangue e os programas de imunização são promovidos, através do uso de cartazes nas salas de espera, folhetos e outras campanhas públicas (MORAIS T.; MORAIS M., 2012; HART, 2000). 
3 METODOLOGIA

O estudo foi do tipo quantitativo, retrospectivo, descritivo, realizado por meio de coleta e análise de dados encontrados nos protocolos de morte encefálica da Central de Notificação, Captação e Distribuição de Órgãos do Distrito Federal (CNCDO - DF).

A coleta de dados foi realizada no espaço físico da Central de Notificação, Captação e Distribuição de Órgãos do Distrito Federal (CNCDO - DF), localizada no complexo do Hospital de Base do DF, no Mezanino, na sala 102 (Setor Médico Hospitalar Sul - Asa Sul, Brasília).

Foram analisados todos os protocolos de morte encefálica (ME) de todas as crianças e adolescentes, de 0 a 18 anos, atendidos com diagnóstico de morte encefálica no DF e que foram incluídos no programa de captação de órgãos, no período de janeiro de 2013 a dezembro de 2016, totalizando uma amostra de 146 pacientes. Inicialmente, a proposta do projeto era pesquisar entre o período de janeiro de 2011 a dezembro de 2015, mas, por falta de acesso a alguns protocolos de 2011 e de 2012, o período foi alterado para janeiro de 2013 a dezembro de 2016 .

O objeto de estudo da pesquisa foram essas crianças e adolescentes já descritos, com diagnóstico de morte encefálica, que configuram justamente os potenciais doadores pediátricos de órgãos e tecidos.

Os critérios de inclusão na amostra foram: pacientes pediátricos, de 0 a 18 anos, que apresentaram de morte encefálica, no DF, no período de janeiro de 2013 a dezembro de 2016. Os critérios de exclusão foram: doação de órgãos in vivo e protocolos não finalizados.

Foi elaborado um instrumento de coleta de dados (apêndice A) com 15 variáveis para a avaliação do perfil epidemiológico dessas crianças e adolescentes: ano de internação, sexo, idade, cor, motivos da internação, maus tratos, causa da morte encefálica, tipo de notificação (pela equipe assistencial, busca ativa pela OPO), local do primeiro atendimento, hospital em que se procedeu e se encerrou 0 protocolo de morte encefálica (hospital notificador), se houve ou não a doação de órgãos, motivos da não doação, órgãos e tecidos mais captados para doação (rim, fígado, coração, pulmão, córneas), hospital em que os órgãos foram retirados. 
A coleta de dados foi realizada no período de fevereiro a maio de 2017. A equipe de pesquisadores foi composta por Bruna Rolim e Marcos Paulo (alunos de medicina do UniCEUB), bem como por Andréa Kairala, médica intensivista pediatra e orientadora da pesquisa. Os alunos foram responsáveis pela pesquisa, leitura e atualização bibliográfica, pela obtenção dos dados referentes aos potenciais doadores de órgãos pediátricos no DF, pela elaboração do relatório parcial, pela elaboração do relatório final e pela elaboração do artigo científico, sempre com orientação da Dra Andréa. A análise dos dados obtidos foi realizada por um estatístico contratado para esse fim.

Realizou-se análise dos dados por meio da estatística descritiva, com 0 objetivo de caracterizar a amostra quanto ao ano de internação, sexo, idade, cor, motivos da internação, maus tratos, causa da morte encefálica, tipo de notificação (pela equipe assistencial, busca ativa pela OPO) e todas as outras variáveis contidas no instrumento de coleta de dados. O número total de doadores efetivos e de não doadores também foi analisado, assim como o número total de órgãos e tecidos captados para doação.

A análise univariada foi descrita em valores absolutos, médias e percentuais (por meio de tabelas). Para a análise de associação entre as variáveis (bivariada), utilizou-se o teste Qui-Quadrado. Tal teste foi usado para descobrir se existe uma associação/relação estatisticamente significante entre as variáveis coletadas e relacionadas à doação de órgãos. Para análise, foi adotado um nível de significância a considerado de 5\%; ou seja, se, ao realizar o teste, o resultado gerado possuiu um valor abaixo de 0,05, concluiu-se que existe relação entre as variáveis. Como exemplo, se o p-valor resultar em valor de $0,001(<0,05)$ demonstra-se alta relação entre as variáveis estudadas.

Para a elaboração do artigo científico e do relatório final, um levantamento bibliográfico e revisão de literatura das pesquisas e assuntos mais recentes na área foi realizado, por meio de bases de dados automatizadas como MEDLINE, SCIELO, PUBMED, LILACS e SECRETARIA DA SAÚDE, utilizando como palavras-chave doação de órgãos, doadores de órgãos, pediátricos, perfil dos potenciais doadores pediátricos, transplantes. O período dos artigos pesquisados foi de 1960 a 2017, em língua inglesa, espanhola e portuguesa.

Por ser um estudo não intervencionista (sem intervenções clínicas), com presença de risco mínimo aos pacientes e familiares, foi proposta a dispensa do 
TCLE (apêndice B), a qual foi aceita. O estudo respeitou as regulamentações nacionais relativas à privacidade e à investigação médica. Em nenhum momento da execução e exposição desse estudo houve identificação dos pacientes ou entrevista de pais ou responsáveis. Foi realizada apenas análise de protocolos finalizados de morte encefálica.

O projeto foi aprovado pelo Comitê de Ética em Pesquisa do Centro Universitário de Brasília, e pelo Comitê de Ética em Pesquisa da Fundação de Ensino e Pesquisa em Ciências da Saúde do DF com números de pareceres 1.882.072 (anexo B) e 1.910.132 (anexo C) do ano de 2016. 


\section{RESULTADOS E DISCUSSÃO}

\subsection{Análise Univariada}

A amostra analisada se refere a 146 potenciais doadores (efetivos e não efetivos), observados ao longo dos últimos 4 anos. A tabela 01 apresenta algumas características dos pacientes pesquisados.

\section{Tabela 01: Características dos pacientes pesquisados}

\begin{tabular}{c|c|c|r}
\hline Variável & Categoria & Qtd & \multicolumn{1}{c}{$\%$} \\
\hline & RN & 1 & 0,7 \\
& Lactente & 25 & 17,1 \\
Faixa de & Pré-escolar & 18 & 12,3 \\
Idade & Escolar & 27 & 18,5 \\
& Adolescente & 75 & 51,4 \\
& Total & $\mathbf{1 4 6}$ & $\mathbf{1 0 0}$ \\
\hline \multirow{2}{*}{ Sexo } & Masculino & 99 & 67,8 \\
& Feminino & 47 & 32,2 \\
& Total & $\mathbf{1 4 6}$ & $\mathbf{1 0 0}$ \\
\hline & Branca & 41 & 28 \\
& Preta & 11 & 7,5 \\
& Parda & 84 & 57,5 \\
& SRC & 10 & 6,8 \\
& Total & $\mathbf{1 4 6}$ & $\mathbf{1 0 0}$ \\
\hline \multirow{2}{*}{ Cor da Pele } & & &
\end{tabular}

Da população analisada verificou-se predominância de adolescentes (51,4\%), sexo masculino $(67,8 \%)$, cor parda $(57,5 \%)$. No que se refere a faixa etária foi observada uma semelhança de porcentagem entre escolares $(18,5 \%)$ e lactentes $(17,1 \%)$; apenas $12,3 \%$ de pré-escolares e $0,7 \%(\mathrm{~N}=1)$ recém-nascidos.

Esses resultados dialogam com os achados por Siebelink (2012a), na Holanda, no qual, de uma amostra de 62 potenciais doadores de órgãos pediátricos, entre 0 a 17 anos, 44\% eram meninas e 56\% eram meninos. No entanto, diferem quanto à faixa etária, na qual 48\% tinham menos de um ano e $74 \%$ tinham menos de 5 anos.

Verifica-se uma semelhança ao comparar os resultados obtidos nesse estudo (maioria da população parda - 57,5\%) com os dados censitários do Brasil, uma vez que o IBGE (2016, p. 17) indica o predomínio da raça parda na Região CentroOeste, com 59,9\% da população. 
O gráfico 01 apresenta os principais motivos de internação dos pacientes. Entre os mais citados, verifica-se a predominância de causas externas $(41,1 \%)$ sendo $21,9 \%$ caracterizado por atropelamento/acidente automobilístico, 18,5\% ocasionado por perfuração por arma de fogo (PAF) e 0,7\% (N=1) por enforcamento. No mais, verifica-se que $13,7 \%$ dos pacientes foram internados em decorrência de tumor cerebral.

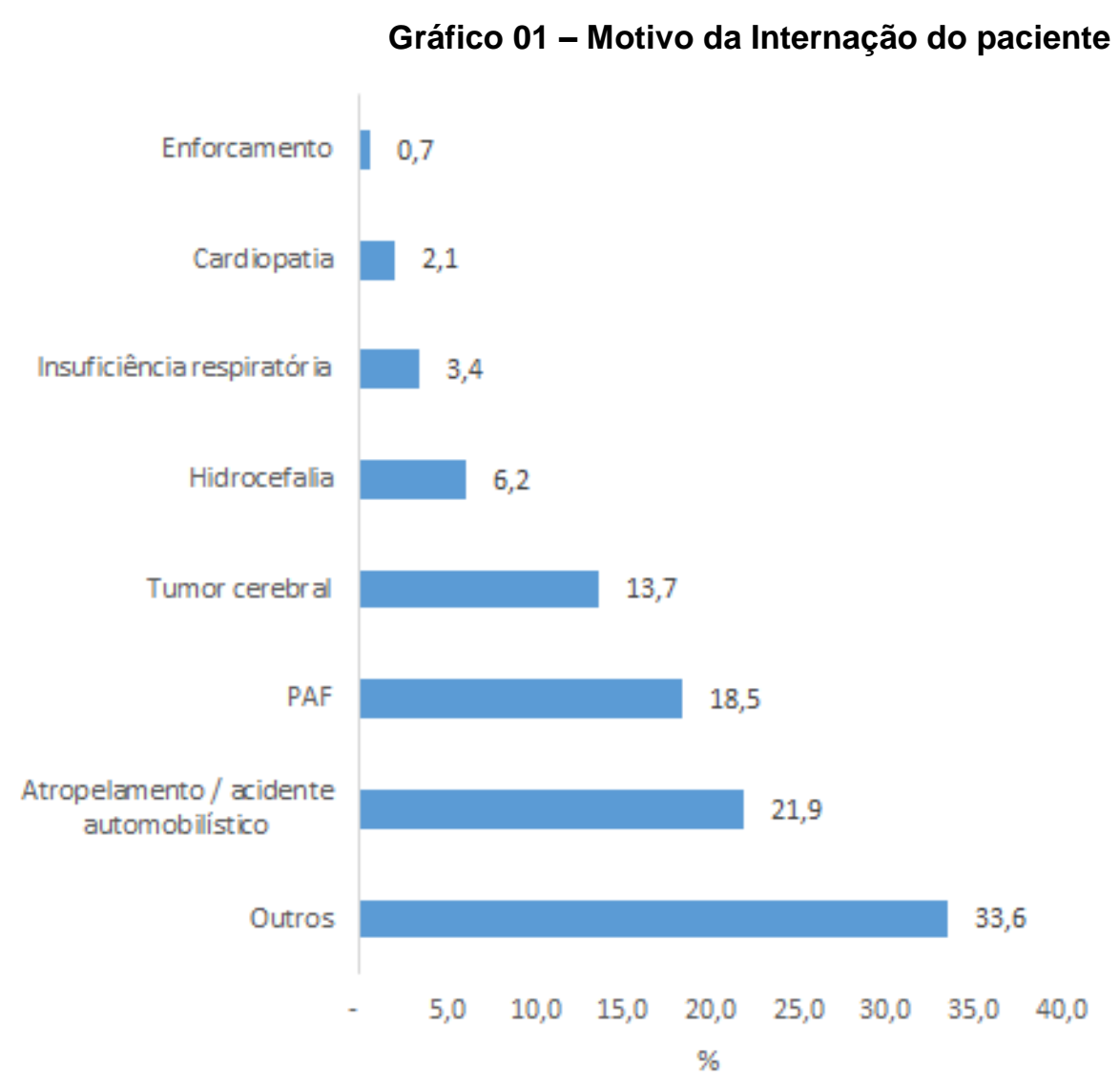

Observa-se ainda, que $33,6 \%$ dos pacientes foram internados por outros motivos, dentre eles: sepse/choque séptico, insuficiência renal, anafilaxia, choque hipovolêmico, plaquetopenia crônica, pneumonia, leucemia e outros tumores, síndrome ALTE, síndrome de Holt Oran, vasculite não especificada, crises convulsivas, púrpura trombocitopênica idiopática, meningoencefalite/meningite, complicações pós-cirúrgicas, linfoma não-hodgkin, afogamento, tentativa de suicídio (queda da ponte), esmagamento por queda de televisão, esmagamento por porteira de ferro, coqueluche severa maligna, H1N1, síndrome de Ondine, queda do telhado, choque elétrico, e complicação pós-parto (no caso do recém-nascido).

Ao analisar as principais causas de ME (gráfico 02), verificou-se predominância de hemorragia de sistema nervoso central (36\% dos casos), seguido de edema cerebral ( $25 \%$ dos casos) e isquemia de sistema nervoso central ( $8 \%)$. Foi 
ainda observado que $4 \%$ das causas da morte encefálica ocorreram devido à herniação cerebral, (seja por edema cerebral, seja por massa expansiva em SNC). Observa-se ainda, que $27 \%$ dos pacientes sofreram morte encefálica por outros motivos, dentre eles: anóxia pós-PCR, abscesso cerebral, hipoperfusão póshipotensão e asfixia perinatal.

A hemorragia de sistema nervoso central como principal causa de morte encefálica na amostra estudada está relacionada à alta incidência de internação por causas externas, que geraram traumatismo cranioencefálico.

De acordo com DuBose e Salim (2008), as patologias que, com maior frequência, conduzem ao diagnóstico de morte encefálica, em adultos, são: o acidente vascular cerebral hemorrágico ou isquêmico ( $A V C$ ), o traumatismo cranioencefálico (TCE) e tumor cerebral. Para Sallum, Rossato e Silva (2011), enquanto a primeira causa incide com maior frequência em uma população acima de 45 anos, os TCEs são prevalentes na população jovem, sobretudo em decorrência das causas externas. $O$ presente estudo corrobora essa premissa e as estatísticas brasileiras do IBGE (2013), quando aponta que o registro de mortes entre jovens do sexo masculino é maior que o verificado entre jovens do sexo feminino.

\section{Gráfico 02 - Motivo da Morte Encefálica}

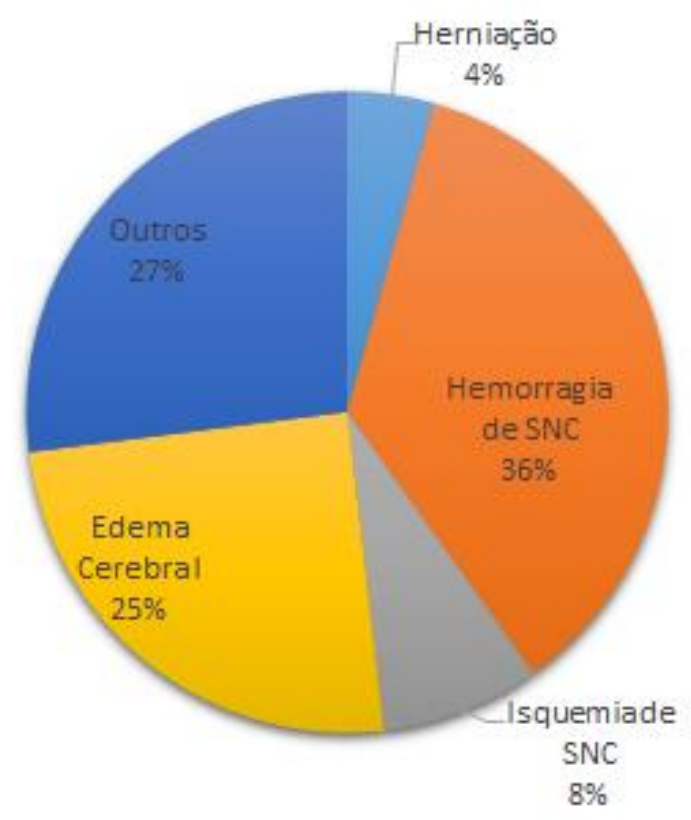

O Gráfico 03 apresenta a rede de hospitais nos quais foram realizados os primeiros atendimentos, como também os hospitais em que foram realizados os protocolos de morte encefálica. 
Gráfico 03 - Tipo de hospital que foi realizado o primeiro atendimento do indivíduo e o hospital que protocolou a morte encefálica.

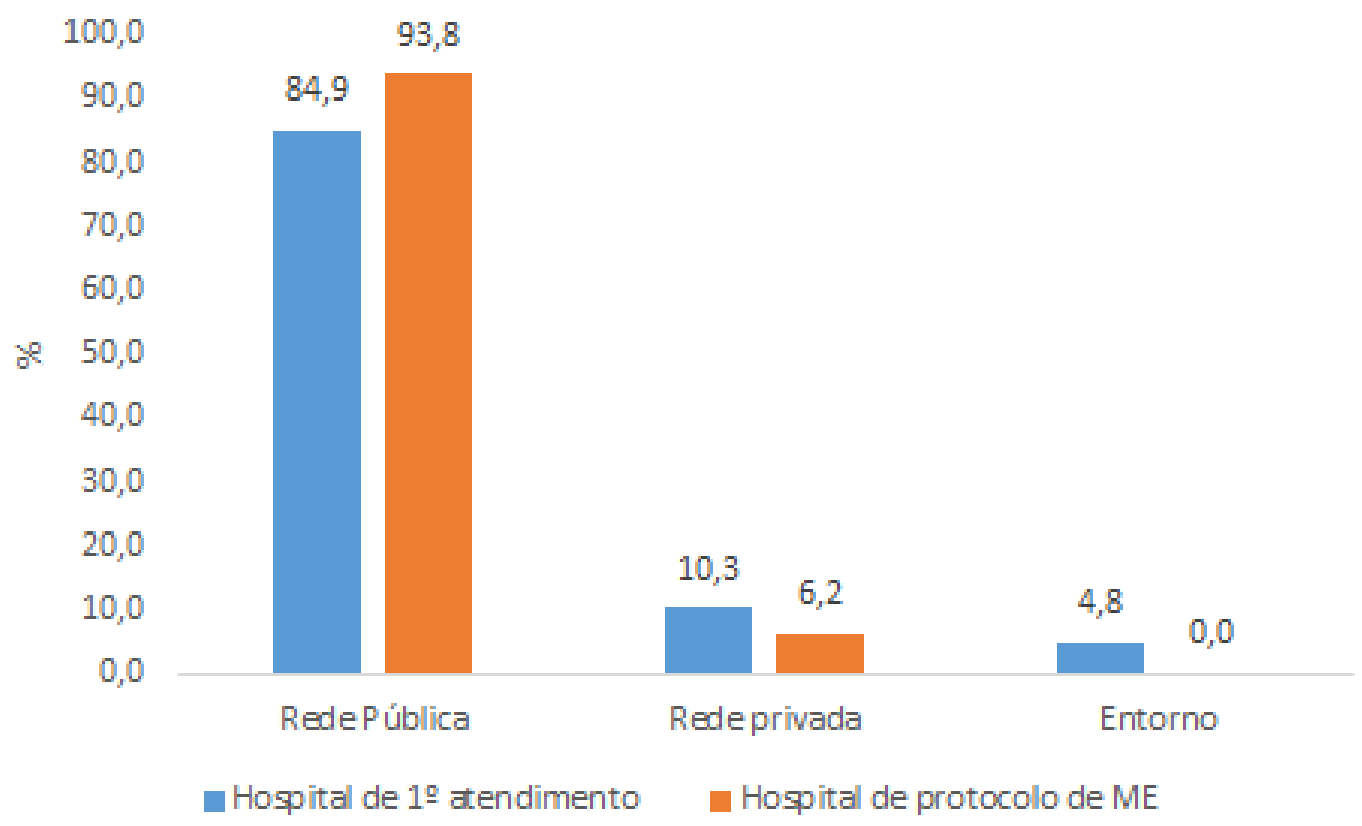

Percebe-se uma predominância de indivíduos que foram atendidos em hospitais de rede pública no primeiro atendimento, o que corresponde a $84,9 \%$ dos pesquisados. Ao analisar em quais hospitais os pacientes da pesquisa tiveram iniciados seus protocolos de ME, percebe-se uma queda do número de indivíduos na rede privada (para $6,2 \%$ ) e nos hospitais do entorno $(0,0 \%)$ do $D F$, e, por consequência, um aumento de indivíduos na rede pública (93,8\%). Logo, sugere-se que os pacientes com agravamento da situação de saúde foram transferidos para hospitais especializados da rede pública do DF.

Esses resultados indicam uma similaridade com um estudo realizado por Freire et al (2013), no qual a maioria dos potenciais doadores encontrava-se internado em hospital público $(86,6)$ em leito de UTI $(68,3 \%)$ e isso ocorre porque cerca de $80 \%$ da população brasileira depende dos serviços públicos de saúde e 0 maior número de leitos de UTI se encontra em hospitais públicos. Além disso, é na UTI que se encontra a maioria dos pacientes com quadro geral grave. Os cuidados intensivos com os potenciais doadores são essenciais, pois contribuem para a melhoria da qualidade do órgão para transplante.

O DF possui, desde 2016, sete superintendências de saúde, de acordo com suas regiões. Cada superintendência é responsável por acompanhar os trabalhos e 
cobrar resultados em uma área do DF. As áreas sob responsabilidade de cada Superintendência de Saúde são: 1) Centro-Norte: Asa Norte, Cruzeiro, Lago Norte, Varjão e rodoviária do Plano Piloto; 2) Centro-Sul: Asa Sul, Guará, Núcleo Bandeirante, Lago Sul, Candangolândia, Riacho Fundo I e II e Park Way; 3) Oeste: Brazlândia e Ceilândia (incluindo Sol Nascente); 4) Sul: Gama e Santa Maria; 5)Sudoeste: Taguatinga, Samambaia e Recanto das Emas; 6) Norte: Sobradinho e Planaltina (incluindo Estância Mestre D'Armas e Arapoanga); 7) Leste: Paranoá e São Sebastião (RODRIGUES, 2016).

\section{Quadro 01 - Distribuição entre o Local de 1ำ atendimento e protocolo de ME}

\begin{tabular}{|c|c|c|c|c|c|c|c|c|c|c|}
\hline \multirow{2}{*}{\multicolumn{2}{|c|}{ Variáveis }} & \multicolumn{9}{|c|}{ Hospital de Protocolo de ME } \\
\hline & & \multirow{2}{*}{\begin{tabular}{r|} 
HBDF \\
30
\end{tabular}} & \multirow{2}{*}{$\begin{array}{c}\text { Centro - } \\
\text { Norte }\end{array}$} & \multirow{2}{*}{$\begin{array}{l}\text { Centro - } \\
\text { Sul }\end{array}$} & \multirow{2}{*}{ Oeste } & \multirow{2}{*}{ Sul } & \multirow{2}{*}{ Sudoeste } & \multirow{2}{*}{ Leste } & \multirow{2}{*}{$\begin{array}{r}\begin{array}{c}\text { Rede } \\
\text { Privada }\end{array} \\
1\end{array}$} & \multirow{2}{*}{$\begin{array}{r}\text { Total } \\
32\end{array}$} \\
\hline \multirow{11}{*}{$\begin{array}{l}\text { Local do } 10 \\
\text { atendimento }\end{array}$} & HBDF & & & & & & & & & \\
\hline & Centro - Norte & 2 & & & & & 1 & & & 3 \\
\hline & Centro - Sul & 5 & & 10 & & & & & & 15 \\
\hline & Oeste & 12 & & 1 & 1 & 1 & & & 1 & 16 \\
\hline & Sul & 11 & 1 & 5 & 1 & 5 & & & & 23 \\
\hline & Sudoeste & 5 & & & & 2 & 4 & & & 11 \\
\hline & Norte & 9 & & 2 & & 2 & & & 1 & 14 \\
\hline & Leste & 6 & & 1 & & & & 3 & & 10 \\
\hline & Rede Privada & 1 & & & & & & & 6 & 7 \\
\hline & Entorno & 8 & 1 & 3 & & & 3 & & & 15 \\
\hline & Total & 89 & 2 & 22 & 2 & 11 & 8 & 3 & 9 & 146 \\
\hline
\end{tabular}

No quadro 01, pode-se perceber que 89 indivíduos, em algum momento passaram pelo HBDF, tenha sido em seu primeiro atendimento ou em um segundo momento (maioria dos casos), na abertura do protocolo da ME; ou seja, $60,95 \%$ dos pacientes da amostra. Isso acontece pois o HBDF é um hospital terciário bem capacitado, centro de referência para casos graves em todo o Centro-Oeste. No mais, 59 pacientes tiveram o protocolo de ME aberto no mesmo local de primeiro atendimento (incluindo os pacientes do HBDF).

Os hospitais e outras unidades de saúde da rede pública do DF que prestaram atendimento aos pacientes da amostra foram: Hospital de Base do Distrito Federal; Hospital Regional da Asa Norte, Hospital da Criança de Brasília ${ }^{1}$, Hospital Universitário de Brasília (Centro-Norte); Hospital Materno Infantil de Brasília, Instituto

\footnotetext{
${ }^{1}$ Os hospitais citados não constam em nenhuma superintendência de saúde, mas foram enquadrados dessa maneira em decorrência de sua localização.
} 
de Cardiologia do Distrito Federal'1, Hospital Regional do Guará (Centro-Sul); Unidade Básica de Saúde (UBS) do Novo Gama, Hospital Regional do Gama, Hospital Regional de Santa Maria (Sul); Hospital Regional de Sobradinho, Hospital Regional de Planaltina (Norte); Unidade de Pronto Atendimento (UPA) de São Sebastião, Hospital Regional do Paranoá (Leste); UPA de Ceilândia, Hospital Regional de Ceilândia, Hospital Regional de Brazlândia (Oeste); Hospital Regional de Samambaia, Hospital Regional de Taguatinga e UPA do Recanto das Emas (Sudoeste).

Os hospitais da rede privada do DF que prestaram atendimento aos pacientes da amostra foram: Hospital Santa Helena, Hospital Anchieta, Hospital Daher, Hospital Santa Luzia, Hospital Santa Marta, Hospital Santa Lúcia e Hospital São Francisco.

As unidades de saúde do Entorno do DF que prestaram atendimento aos pacientes da amostra foram: Hospital de Águas Lindas de Goiás (GO), UPA do Valparaíso - GO, Hospital de Santo Antônio do Descoberto - GO, UPA de Formosa - GO, Hospital Municipal de Padre Bernardo - GO, Hospital Municipal de Unaí MG, UBS de Cinelândia - GO e Hospital de Cristalina - GO.

\begin{tabular}{|c|c|c|c|}
\hline Variável & Categoria & Qtd & $\%$ \\
\hline \multirow{3}{*}{$\begin{array}{c}\text { Sofreu Maus } \\
\text { Tratos? }\end{array}$} & Sim & 2 & 1,4 \\
\hline & Não & 144 & 98,6 \\
\hline & Total & 146 & 100,0 \\
\hline \multirow{4}{*}{ Notificação } & Busca ativa da CNCDO & 37 & 25,4 \\
\hline & Notificação pela equipe do hosp. & 100 & 68,5 \\
\hline & $\mathrm{NI}$ & 9 & 6,1 \\
\hline & Total & 146 & 100,0 \\
\hline \multirow{3}{*}{$\begin{array}{l}\text { Tipo de } \\
\text { Doador }\end{array}$} & Efetivo & 50 & 34,2 \\
\hline & Não efetivo & 96 & 65,8 \\
\hline & Total & 146 & 100,0 \\
\hline
\end{tabular}

NI: Não informado

Atualmente os maus-tratos contra crianças e adolescentes são reconhecidos como um complexo problema de saúde pública, com elevado custo financeiro, social e emocional para a sociedade. No Brasil, embora abordado em legislações anteriores, foi somente em 1990, com a implantação do Estatuto da Criança e do Adolescente (ECA), através da Lei Federal n॰ 8.069, que se tornou compulsória a notificação por parte do profissional de saúde de casos suspeitos ou confirmados de 
maus tratos contra crianças e adolescentes. Mesmo com a obrigatoriedade de notificação, o maior interesse no tema e nos dados que mostram que nosso país apresenta altos índices de violência, há poucas estatísticas concretas da incidência de casos de maus-tratos a crianças no Brasil. Isso se deve à dificuldade de definição, reconhecimento e denúncia por parte dos profissionais da saúde (PICINI et al, 2017). Do total da amostra, há suspeita de 2 casos de maus tratos (1,4\%); e não há descrição clara sobre quais pacientes sofreram lesões por causas intencionais.

Quanto ao processo de notificação da morte encefálica, verifica-se que $25,4 \%$ dos casos declarados foram por busca ativa pela equipe (OPO/CNCDO-DF) sendo o restante por notificação da equipe assistencial (68,5\%) do hospital; em 6,1\% (N=9) dos prontuários não havia informação sobre esse dado. Os resultados são similares à pesquisa de Fusco et al (2009), na qual (85.1\%) das notificações foram espontâneas, ou seja, identificadas pelo próprio hospital onde se encontrava o doador.

\section{Gráfico 04 - Potenciais Doadores e Doadores Efetivos}

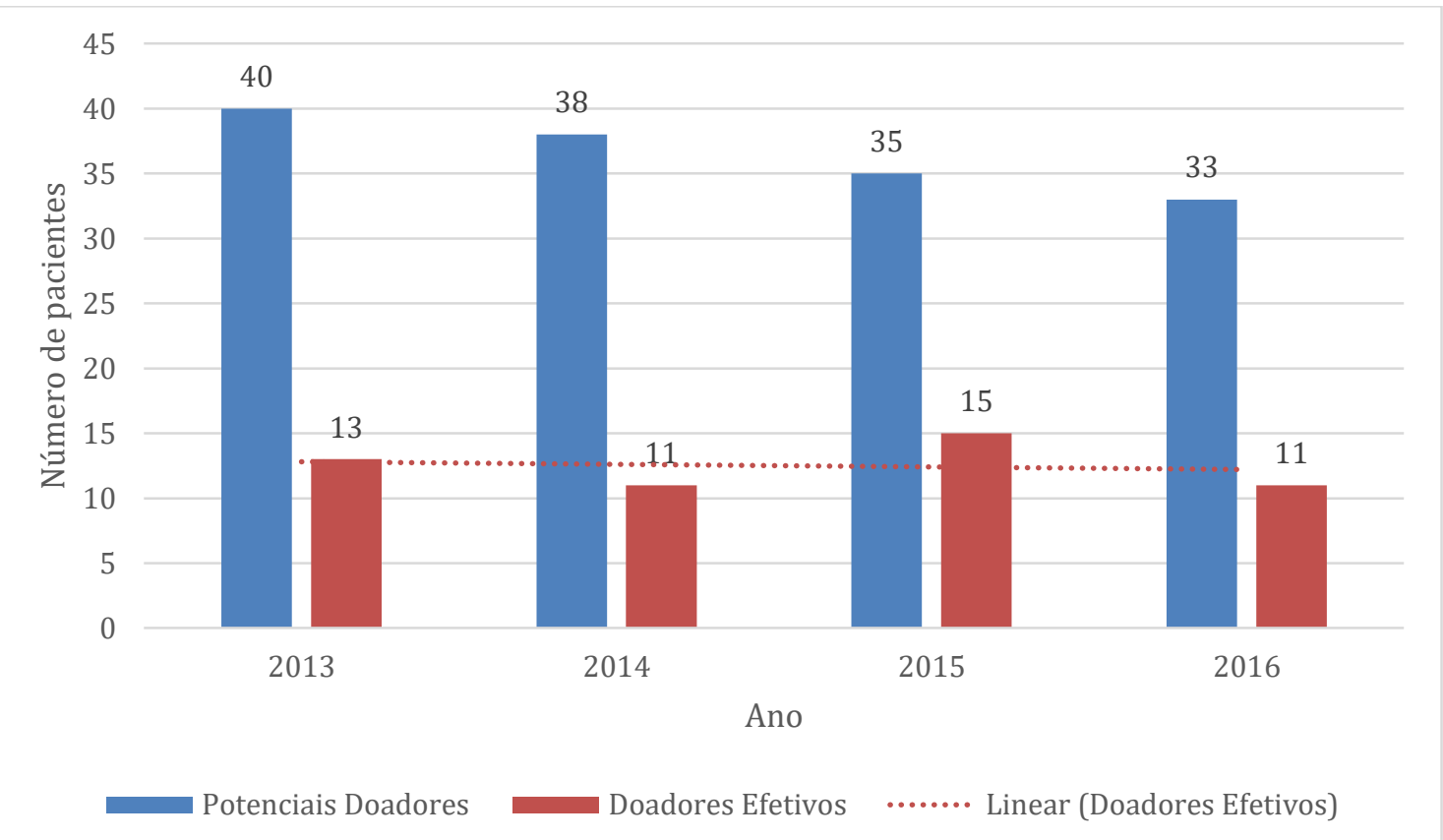

Dos 146 possíveis doadores (população analisada), apenas 34,2\% ( $N=50)$ efetivaram a doação de órgãos, com uma média de 12,5 doadores por ano. Houve diminuição de doadores, de 2013 para 2014 e de 2015 para 2016, associada a uma 
diminuição constante, nesses 4 anos, do número de protocolos de $\mathrm{ME}$ pediátricos (de doadores e não doadores).

Esses resultados vão ao encontro dos achados por Siebelink (2012) e Freire et al (2013) nos quais $41,93 \%$ e $30 \%$ das doações foram efetivadas, respectivamente.

Ao se analisar o gráfico 05 , verifica-se que os motivos mais frequentes no grupo estudado para a não-doação de órgãos foram: parada cardiorrespiratória antes do encerramento do protocolo, que representa $36 \%$ dos casos, seguida pela recusa dos familiares, com $25 \%$ dos casos; neoplasias malignas (18\%) e doenças infectocontagiosas (6\%). Outras causas foram: contra indicação médica não especificada, falência de múltiplos órgãos e doença autoimune.

A recusa familiar foi bem menos expressiva quando comparada aos resultados de Siebelink (2012) e Freire et al (2013), nos quais 54,83\% e 38,1\% dos casos houve recusa familiar, respectivamente.

\section{Gráfico 05 - Principais motivos da não doação de órgãos}

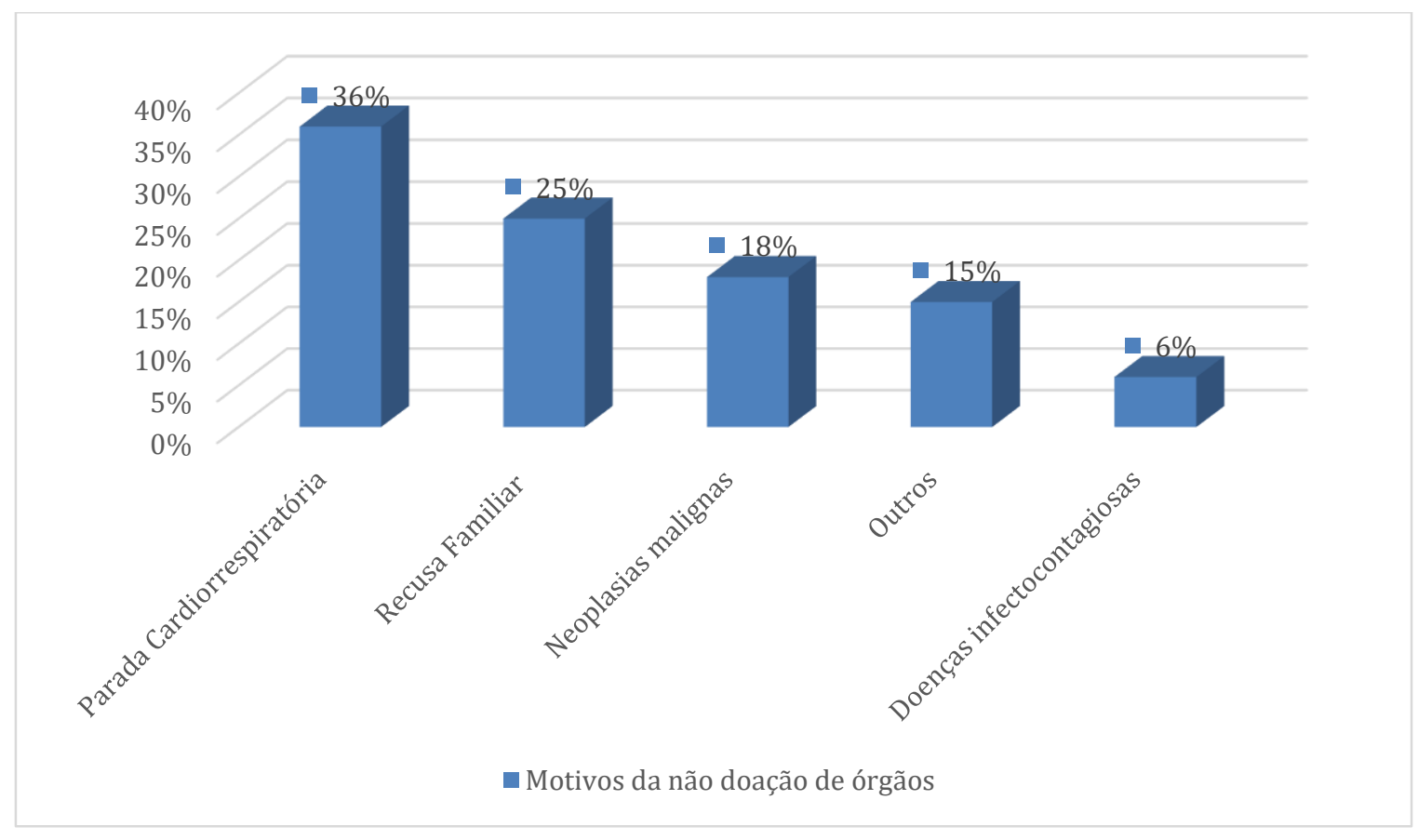

O diagnóstico de morte encefálica (ME) envolve dor e sofrimento principalmente quando da morte de crianças, fato que influencia negativamente na decisão pela doação de órgãos. Os dados sobre os motivos da não autorização por parte da família não estavam registrados nos prontuários. No entanto, segundo a ABTO (2014a), a principal justificativa de negação é a falta de conhecimento sobre a 
irreversibilidade da morte encefálica; outros motivos incluem falta de diálogo sobre a doação de órgãos antes da morte, falta de consenso entre os pais (geralmente a recusa maior é da mãe), e desejo de manter o corpo íntegro. Para mudar esse quadro, campanhas têm sido realizadas com intuito de que cada brasileiro que deseje que seus órgãos sejam doados para transplante, em caso de ME, avise a família desse desejo. Provavelmente, na hora da dor da perda, os familiares irão autorizar a doação.

Uma sequência própria de eventos fisiológicos ocorre nos pacientes críticos que estão evoluindo para morte encefálica, como a parada cardiorrespiratória e a instabilidade hemodinâmica. Para fins de transplantes, é importante a manutenção dos órgãos e tecidos em condições favoráveis, caso contrário haverá um funcionamento ineficaz ou falência dos órgãos. Portanto, após o diagnóstico da morte encefálica e o consentimento familiar, o tratamento do doador tem por objetivo otimizar a perfusão tecidual, assegurando a viabilidade dos órgãos. O tempo prolongado para a confirmação a ME pode ser um dos motivos que leva o paciente à parada cardiorrespiratória antes do fechamento do protocolo (BARRETO et al, 2016).

Quanto aos tipos de órgãos e tecidos coletados, em média são doados aproximadamente $3^{2}$ tipos por paciente (2,88 valores exato). Verifica-se na tabela 3 a predominância dos rins (34\%), seguido de fígado (25,7\%), córneas (25\%) e coração (15,3\%). No período analisado, não houve nenhuma doação de pulmão. No mais, a respeito do hospital onde é feita a retirada, a grande maioria, $78 \%(\mathrm{~N}=39)$, foi realizada no Instituto de Cardiologia do DF (ICDF), seguido pelo Hospital de Base $(\mathrm{N}=7 ; 14 \%)$, Hospital Materno Infantil ( $\mathrm{N}=3 ; 6 \%)$ e Hospital Regional de Santa Maria $(\mathrm{N}=1 ; 2 \%)$.

Os resultados dialogam com os estudos em adultos de Moraes et al (2009) e Fusco et al (2009), em que os órgãos e tecidos mais doados respectivamente foram os rins $(81,28 \%$ e $88,8 \%)$ seguidos de fígado $(80,21 \%$ e $87,1 \%)$, córneas $(60,5 \%$ e $79,3 \%$ ) e coração $(18,72 \%$ e $54,8 \%)$. Os rins são órgãos mais utilizados, em comparação aos demais órgãos, pois ele possui vantagens, como tempo prolongado

${ }^{2}$ Quanto aos órgãos que possuem pares, não foi possível identificar a quantidade que foi doada pelos indivíduos pesquisados. 
de isquemia fria (o órgão fora do corpo sob refrigeração pode ser utilizado para transplante por até 36 horas) e retirada de doadores sem batimentos cardíacos.

Tabela 3 - Órgãos doados

\begin{tabular}{c|c|c|c}
\hline Variável & Categoria & Qtd & $\%$ \\
\hline \multirow{4}{*}{ Órgãos doados } & Rim & 49 & 34,0 \\
& Fígado & 37 & 25,7 \\
& Coração & 22 & 15,3 \\
& Córneas & 36 & 25,0 \\
& Total & 50 & $100 \%$ \\
\hline
\end{tabular}

4.2 Análise Bivariada

Tabela 4.1 - Perfil dos indivíduos pesquisados por tipo de doador

\begin{tabular}{|c|c|c|c|c|c|c|}
\hline \multirow{3}{*}{ Variável } & \multirow{3}{*}{ Categoria } & \multicolumn{4}{|c|}{ Tipo de doador de órgãos } & \multirow{3}{*}{ p-valor } \\
\hline & & \multicolumn{2}{|c|}{ Efetivos } & \multicolumn{2}{|c|}{ Não Efetivos } & \\
\hline & & Qtd & $\%$ & Qtd & $\%$ & \\
\hline \multirow{3}{*}{ Sexo } & Masculino & 40 & 80,0 & 59 & 61,5 & \multirow{3}{*}{0,023} \\
\hline & Feminino & 10 & 20,0 & 37 & 38,5 & \\
\hline & Total & 50 & 100,0 & 96 & 100,0 & \\
\hline \multirow{4}{*}{ Cor da Pele } & Branca & 11 & 22,0 & 30 & 34,9 & \multirow{4}{*}{0,0268} \\
\hline & Preta & 5 & 10,0 & 6 & 7,0 & \\
\hline & Parda & 34 & 68,0 & 50 & 58,1 & \\
\hline & Total & 50 & 100,0 & 86 & 100,0 & \\
\hline \multirow{5}{*}{$\begin{array}{l}\text { Faixa de } \\
\text { Idade }\end{array}$} & RN/Lactente & 5 & 10,0 & 21 & 21,9 & \multirow{5}{*}{0,03184} \\
\hline & Pré-escolar & 8 & 16,0 & 10 & 10,4 & \\
\hline & Escolar & 5 & 10,0 & 22 & 22,9 & \\
\hline & Adolescente & 32 & 64,0 & 43 & 44,8 & \\
\hline & Total & 50 & 100,0 & 96 & 100,0 & \\
\hline
\end{tabular}

Ao analisar a tabela 4.1, verifica-se que no grupo de indivíduos que doaram órgãos, $80 \%$ são do sexo masculino e $20 \%$ do sexo feminino. Ao verificar o grupo dos que não doaram órgãos, verifica-se um aumento do grupo de indivíduos do sexo feminino. Os dados mostram que há uma significância estatística em relação aos pacientes do sexo feminino a não doarem os órgãos ( $p$-valor 0,023 ).

Quanto a cor da pele percebe-se que apenas 22\% dos doadores efetivos são da cor branca, no entanto percebe-se um crescimento para 34,9\% ao analisar este tipo de pele no grupo dos que não doaram órgãos. Os pacientes pretos e pardos possuem um percentual maior no grupo dos doadores efetivos. Como o p-valor é 
0,0268 (inferior a 0,05), infere-se que o tipo de cor da pele possui influencia na doação de órgãos ou não do grupo pesquisado.

Em relação a faixa etária, 64,0\% dos doadores efetivos eram adolescentes; porém, no grupo dos não efetivos, esta faixa etária representa apenas $44,8 \%$. O pvalor 0,03184 sugere que a faixa de idade influencia na doação ou não de órgãos.

Tabela 4.2 - Perfil dos indivíduos pesquisados por tipo de doador

\begin{tabular}{|c|c|c|c|c|c|c|}
\hline \multirow{3}{*}{ Variável } & \multirow{3}{*}{ Categoria } & \multicolumn{4}{|c|}{ Tipo de doador de órgão } & \multirow{3}{*}{ p-valor } \\
\hline & & \multicolumn{2}{|c|}{ Efetivos } & \multicolumn{2}{|c|}{ Não Efetivos } & \\
\hline & & Qtd & $\%$ & Qtd & $\%$ & \\
\hline \multirow{4}{*}{$\begin{array}{l}\text { Local do } 19 \\
\text { Atendimento }\end{array}$} & Rede pública & 44 & 88,0 & 80 & 83,3 & \multirow{4}{*}{0,001} \\
\hline & Rede Privada & 0 & 0,0 & 7 & 7,3 & \\
\hline & Entorno & 6 & 12,0 & 9 & 9,4 & \\
\hline & Total & 50 & 100,0 & 96 & 100,0 & \\
\hline \multirow{7}{*}{$\begin{array}{l}\text { Motivo da } \\
\text { Internação }\end{array}$} & $\begin{array}{c}\text { Atropelamento / acidente } \\
\text { automobilístico }\end{array}$ & 17 & 43,6 & 15 & 26,3 & \multirow{7}{*}{0,00045} \\
\hline & PAF & 16 & 41,0 & 11 & 19,3 & \\
\hline & Hidrocefalia & 3 & 7,7 & 6 & 10,5 & \\
\hline & Tumor cerebral & 2 & 5,1 & 18 & 31,6 & \\
\hline & Cardiopatia & 0 & 0,0 & 3 & 5,3 & \\
\hline & Insuficiência respiratória & 1 & 2,6 & 4 & 7,0 & \\
\hline & Total & 39 & 100,0 & 57 & 100,0 & \\
\hline
\end{tabular}

Quanto ao motivo de internação verifica-se que no grupo de doadores efetivos há uma predominância de causas externas, tais como atropelamento/acidente automobilístico (43,6\%) e PAF (41,0\%). Porém ao analisar os não doadores verificase que as causas externas não têm predominância neste grupo, sendo o motivo "Tumor cerebral" o mais encontrado dentre estes. O p-valor informa que há relação entre motivo da internação e tipo de doador. Sugere-se que causas externas têm forte influência se o paciente será efetivo ou não na doação de órgãos.

Os resultados do presente estudo concordam com Oliveira et al (2016), quando diz que o nível crescente e inaceitável de violência no Brasil parece estar contribuindo para o aumento dos transplantes de órgãos no país. O número elevado de mortes de jovens por causas externas cria um contexto favorável à doação de órgãos, visto que se trata, na maioria dos casos, dos órgãos sadios.

Quanto ao local de primeiro atendimento, verifica-se que $88 \%$ dos doadores efetivos tiveram como primeiro local de atendimento os hospitais de rede pública do Distrito Federal. No entanto, percebe-se que este percentual cai para $83,3 \%$ ao 
analisar os não doadores. Além disso, nenhum doador teve como local de primeiro atendimento a rede privada.

Quanto ao grupo de pacientes de doadores efetivos verifica-se, na tabela 5, que a principal causa de ME é a Hemorragia de SNC (38,8\%). No entanto, as principais causas de ME de doadores não efetivos estão na categoria "Outros" $(35,2 \%)$, já citados. Apesar do p-valor demonstrar forte relação entre essas variáveis, é importante analisar com cautela as causas da ME classificadas como "Outros".

Ao analisar os doadores efetivos, verifica-se que a notificação da ME pela equipe do hospital corresponde a $60,4 \%$ do devido grupo. Quando analisados os doadores não efetivos, verifica-se que essa notificação, realizada pela equipe do hospital, aumenta para 79,8\%. O p-valor de 0,037 informa que há relação entre o tipo de notificação e o doador potencial. Isso pode significar que a busca ativa de pacientes em ME realizada pela equipe da CNCDO/OPO possui uma maior especificidade ao identificar um paciente em ME, quando comparada à notificação pela equipe do hospital; enquanto a notificação pela equipe do hospital possui uma maior sensibilidade em identificar e notificar mortes encefálicas.

Tabela 5 - Informações sobre os indivíduos pesquisados, segundo tipo de doador

\begin{tabular}{|c|c|c|c|c|c|c|}
\hline \multirow{3}{*}{ Variável } & \multirow{3}{*}{ Categoria } & \multicolumn{4}{|c|}{ Tipo de doador de órgão } & \multirow{3}{*}{$p$-valor } \\
\hline & & \multicolumn{2}{|c|}{ Efetivos } & \multicolumn{2}{|c|}{ Não Efetivos } & \\
\hline & & Qtd & $\%$ & Qtd & $\%$ & \\
\hline \multirow{6}{*}{ Causa da ME } & Herniação & 1 & 2,0 & 5 & 5,7 & \multirow{6}{*}{0,01013} \\
\hline & Hemorragia de SNC & 19 & 38,8 & 30 & 34,1 & \\
\hline & Isquemia de SNC & 6 & 12,2 & 5 & 5,7 & \\
\hline & Edema Cerebral & 17 & 34,7 & 17 & 19,3 & \\
\hline & Outros & 6 & 12,2 & 31 & 35,2 & \\
\hline & Total & 49 & 100 & 88 & 100,0 & \\
\hline \multirow{3}{*}{$\begin{array}{l}\text { Hospital do } \\
\text { protocolo de ME }\end{array}$} & Rede pública & 48 & 96,0 & 89 & 92,7 & \multirow{3}{*}{0,7341} \\
\hline & Rede Privada & 2 & 4,0 & 7 & 7,3 & \\
\hline & Total & 50 & 100,0 & 96 & 100,0 & \\
\hline \multirow{3}{*}{$\begin{array}{l}\text { Notificação da } \\
\text { ME }\end{array}$} & Busca ativa & 19 & 39,6 & 18 & 20,2 & \multirow{3}{*}{0,037} \\
\hline & Notificação pela equipe & 29 & 60,4 & 71 & 79,8 & \\
\hline & Total & 48 & 100,0 & 89 & 100,0 & \\
\hline
\end{tabular}




\section{CONCLUSÕES}

O presente estudo permitiu uma reflexão e uma melhor compreensão sobre o processo de doação de órgãos pediátricos, uma vez que possibilitou conhecer as características epidemiológicas e a efetividade da doação em potenciais doadores pediátricos de órgãos e tecidos para transplantes no Distrito Federal. Identificou-se uma amostra de 146 pacientes, com predominância do sexo masculino, adolescentes, de raça parda. Os resultados mostraram que os potenciais doadores, em sua maioria, encontravam-se internados em hospital público, e o principal motivo de internação foram as causas externas (por atropelamento; por perfuração por arma de fogo e por enforcamento).

Dessa forma, adolescentes pardos do sexo masculino são mais vulneráveis à morte encefálica por causas externas, em sua maioria evitáveis. É preciso uma maior atenção à situação de segurança dessa população pelas autoridades governamentais.

A principal causa de ME foi hemorragia do sistema nervoso, associada a traumatismo cranioencefálico. Houve pouquíssimos casos de maus-tratos, no entanto, a grande maioria dos protocolos não apresentava descrição clara sobre quais pacientes sofreram lesões por causas intencionais.

Apenas $34,2 \%$ da amostra efetivaram a doação de órgãos, com uma média de 12,5 doadores por ano. O motivo mais frequente no grupo estudado para a nãodoação de órgãos foi a parada cardiorrespiratória antes do encerramento do protocolo, seguida da recusa familiar. Quanto à cor da pele, apenas 22\% dos doadores efetivos são da cor branca. Os órgãos e tecidos mais doados respectivamente foram rins, fígado, córneas e coração. No período analisado, não houve nenhuma doação de pulmão. A grande maioria das retiradas dos órgãos aconteceu no Instituto de Cardiologia do DF (ICDF), em decorrência de ser um centro especializado em transplante de coração.

Verificou-se ainda que a maioria das notificações foram espontâneas, ou seja, identificadas pelo próprio hospital onde se encontrava o doador. Isso significa que há uma maior conscientização das equipes de saúde em notificar a CNCDO/DF sobre a suspeita de $\mathrm{ME}$ e isso tem relação com um maior preparo e eficiência das equipes assistenciais. O estudo conclui ainda que a busca ativa de pacientes em ME realizada pela equipe da CNCDO/OPO possui uma maior especificidade ao 
identificar um paciente em ME, enquanto a notificação pela equipe do hospital possui uma maior sensibilidade em identificar e notificar mortes encefálicas.

Seguir o protocolo para a definição de ME é fundamental para garantir a qualidade das ações e a segurança de todo o processo doação-transplante. No entanto, as relações humanitárias presentes nesse processo são extremamente importantes e não podem ser esquecidas, por isso, é de grande valia que a equipe de saúde tenha conhecimento das características do potencial doador. Tanto aquelas relacionadas aos aspectos físicos e biológicos, o que auxiliará no cuidado da manutenção deste, quanto as relativas aos aspectos sociais e emocionais, pois estas garantirão um maior envolvimento entre os profissionais de saúde e os familiares, contribuindo assim para reduzir a recusa familiar, melhorando, dessa forma, o número de doações de órgãos e tecidos.

O estudo contou com limitações, como a impossibilidade de análise das causas que levam tantas crianças e adolescentes a sofrerem parada cardiorrespiratória antes do fechado do protocolo de ME. Além disso, não foi possível avaliar a taxa de consentimento com a doação, apenas a taxa de recusa familiar, e os motivos da negação da doação não estavam descritos nos protocolos. Há que se destacar ainda o reduzido número de pesquisas com foco no objeto de estudo. Sugere-se então que mais pesquisas relacionadas ao assunto sejam feitas, na tentativa de buscas por mais fatores que influenciem negativamente na doação de órgãos.

O processo de doação de órgãos tem, em geral, uma repercussão boa na vida dos familiares, e apesar da dor, costuma ser uma experiência positiva, uma vez que pode confortar, dar satisfação e até ser uma honra, pois significa o bem para outras pessoas. No entanto, quando se trata da morte de um filho, principalmente de uma criança, seu enfrentamento é demasiadamente sofrido, de difícil assimilação pelos pais e, quando se apresenta a possibilidade de que seus órgãos sejam doados, o sofrimento pode ser ainda maior. Portanto, é preciso conscientizar os familiares da importância da doação e da segurança em relação ao diagnóstico de $\mathrm{ME}$, mesmo que seja um desafio para as equipes de saúde. É necessária a citação nos prontuários médicos do motivo da negação da doação. A falta de consenso entre os pais pode ser resolvida e as dúvidas sobre o diagnóstico de ME podem ser esclarecidas, facilitando a abordagem sobre o assunto, aumentando assim o número de doadores efetivos no país. 
É necessário, como aponta a Associação Brasileira de Transplantes de Órgãos, planejar estratégias de incremento no transplante pediátrico no Brasil. É preciso desenvolver um processo educativo baseado em campanhas de conscientização, no sentido de melhorar os índices de recusa familiar para doação de órgãos. É preciso ainda que sejam tomadas medidas de educação contínua entre profissionais sobre a importância do registro no prontuário de todas as informações de forma fidedigna, fator imprescindível para tomadas de decisão gerenciais.

Tal realidade exige também dos órgãos públicos ações mais efetivas de políticas públicas que proporcionem uma melhor divulgação do processo de doação de órgãos e tecidos na sociedade, além de proporcionar subsídios adequados para a efetivação do processo. 
REFERÊNCIAS BIBLIOGRÁFICAS

AMERICAN ACADEMY OF PEDIATRICS. Pediatric Organ Donation and Transplantation. Pediatrics, v. 109, n. 5, p. 982-984, mai. 2002.

ASSOCIAÇÃO BRASILEIRA DE TRANSPLANTES DE ÓRGÃOS (ABTO). Registro Brasileiro de Transplantes (RBT) - Dimensionamento dos transplantes no Brasil e em cada estado (2005-2012). São Paulo, 2012. 100 p.

ASSOCIAÇÃO BRASILEIRA DE TRANSPLANTES DE ÓRGÃOS (ABTO). Registro Brasileiro de Transplantes (RBT) - Dimensionamento dos transplantes no Brasil e em cada estado (2006-2013). São Paulo, 2013. 81 p.

ASSOCIAÇÃO BRASILEIRA DE TRANSPLANTES DE ÓRGÃOS (ABTO). 47\% das famílias se recusam a doar órgão de parente com morte cerebral. 2014a. Disponível em: <http://www.abto.org.br/abtov03/default.aspx?c=1063>. Acesso em: 10 ago. 2017.

ASSOCIAÇÃO BRASILEIRA DE TRANSPLANTES DE ÓRGÃOS (ABTO). Registro Brasileiro de Transplantes (RBT) - Dimensionamento dos transplantes no Brasil e em cada estado (2007-2014). São Paulo, 2014b. 85 p.

ASSOCIAÇÃO BRASILEIRA DE TRANSPLANTES DE ÓRGÃOS (ABTO). Registro Brasileiro de Transplantes (RBT) - Dimensionamento dos transplantes no Brasil e em cada estado (2008-2015). São Paulo, 2015. 88 p.

ASSOCIAÇÃO BRASILEIRA DE TRANSPLANTES DE ÓRGÃOS (ABTO). Registro Brasileiro de Transplantes (RBT) - Dimensionamento dos transplantes no Brasil e em cada estado (2009-2016). São Paulo, 2016. 89 p.

BARRETO, B. S.; SANTANA, R. J. B.; NOGUEIRA, E. C.; FERNANDEZ, B. O.; BRITO, F. P. G. Fatores relacionados à não doação de órgãos de potenciais doadores no estado de Sergipe, Brasil. Revista Brasileira de Pesquisa em Saúde, Vitória, v. 18, n. 3, p. 40-48, jul-set. 2016.

BONFADINI, G.; ROISMAN, V.; PRINZ, R.; SARLO, R.; ROCHA, E.; CAMPOS, M. Doação e fila de transplante de córnea no Estado do Rio de Janeiro. Revista Brasileira de Oftalmologia, v. 73, n. 4, p. 237-242. 2014.

BOUSSO, R. S. O processo de decisão familiar na doação de órgãos do filho: uma teoria substantiva. Texto \& Contexto - Enfermagem, Florianópolis, v. 17, n. 1, p. 45-54, jan/mai. 2008.

BRASIL. Decreto n. 2.268, de 30 de junho de 1997. Regulamenta a Lei n. 9.434, de 4 de fevereiro de 1997, que dispõe sobre a remoção de órgãos, tecidos e partes do corpo humano para fins de transplante e dá outras providências. Brasília: Diário Oficial da União, jul. 1997a. 
BRASIL. Lei n. 8.069, de 13 de julho de 1990. Dispõe sobre o Estatuto da Criança e do Adolescente e dá outras providências. Brasília: Diário Oficial da União, jul. 1990.

BRASIL. Lei n. 9.434, de 4 de fevereiro de 1997. Dispõe sobre a remoção de órgãos, tecidos e partes do corpo humano para fins de transplante e tratamento e dá outras providências. Brasília: Diário Oficial da União, fev. 1997b.

CAMARGO, S. M. Doação de órgãos - uma questão cultural. Revista Textual, Rio Grande do Sul, v. 1, n. 12, p. 12-17, out. 2009.

COLUMBIA UNIVERSITY MEDICAL CENTER. Cardiac Transplant Program. History of Medicine: First Pediatric Heart Transplant. 2015. Disponível em: $<$ http://columbiasurgery.org/node/7696/The\%20Mysterious\%20Appendix>. Acesso em: 30 jul. 2017.

CONSELHO FEDERAL DE MEDICINA (CFM). Resolução CFM nำ1.480, de 8 de agosto de 1997. Determina os procedimentos para a determinação de morte encefálica. Diário Oficial da União, Brasília, 1997. 4 p.

CONSELHO FEDERAL DE MEDICINA (CFM). Resolução CFM n. 1.826, de 24 de outubro de 2007. Dispõe sobre a legalidade e o caráter ético da suspensão dos procedimentos de suportes terapêuticos quando da determinação de morte encefálica de indivíduo não doador. Diário Oficial da União, Brasília, 2007. 133 p.

DUBOSE, J.; SALIM, A. Agressive organ donor management protocol. Journal of Intensive Care Medicine, Cambridge, v. 23, n. 6, p. 367 - 375. 2008.

FERREIRA, U (Ed.). Captação de órgãos para transplante. São Paulo: Gráfica e Editora Tecla Tipo, 1997. 207 p.

FREIRE, I. L. S.; VASCONCELOS, Q. L. D. A. Q.; ARAÚJO, R. O.; PINTO, J. T. J. M.; TORRES, G. V. Caracterização dos potenciais doadores de órgãos e tecidos para transplantes. Revista de Enfermagem UFPE online, Recife, v. 7, n. 1, p. 184-191, jan. 2013.

FUSCO, C. C.; MARCELINO, C. A. G.; ARAÚJO, M. N.; AYOUB, A. C.; MARTINS, C. P. Perfil dos doadores efetivos de múltiplos órgãos e tecidos viabilizados pela Organização de Procura de Órgãos de uma instituição pública de cardiologia. Jornal Brasileiro de Transplantes, v. 12, n. 2, abr/jun. 2009.

GARCIA, C. D; PEREIRA, J. D; GARCIA, V. D. Doação e transplante de órgãos e tecidos. São Paulo: Segmento Farma, 2015. 560 p.

HARDY, J. D.; WEBB, W. R.; DALTON JUNIOR, M. L.; WALKER JUNIOR, G. R. Lung homotransplantation in man. Journal of the American Medical Association, Chicago, v. 186, p. 1065 - 1074. 1963.

HART, C. Early education can smooth path for organ donor family. American Academy of Pediatrics News, v. 17. 2000. 
HUANG, J.; WANG, H.; FAN, S. T.; ZHAO, B.; ZHANG, Z.; HAO, L.; HUO, F.; LIU, Y. The national program for deceased organ donation in China. Transplantation, $v$. 96, n. 1, p. 5-9, jul. 2013.

INCOR - Instituto do Coração do Hospital das Clínicas - Núcleo de Comunicação Institucional - HCFMUSP. Feito tem duplo ineditismo no país: implante de ventrículo artificial em tão tenra idade e maior sobrevida com o aparelho nessa faixa etária. Sugestão de Pauta, São Paulo, 2015.

INSTITUTO BRASILEIRO DE GEOGRAFIA E ESTATÍSTICA (IBGE). Estudos e pesquisas. Informação demográfica e socioeconômica número 32 . Síntese de indicadores sociais: uma análise das condições de vida da população brasileira: 2013. Rio de Janeiro, 2013. 266 p.

INSTITUTO BRASILEIRO DE GEOGRAFIA E ESTATÍSTICA (IBGE). Estudos e pesquisas. Informação demográfica e socioeconômica número 36 . Síntese de indicadores sociais: uma análise das condições de vida da população brasileira: 2016. Rio de Janeiro, 2016. 146 p.

JOFFE, A. R.; ANTON, N. Brain death: understanding of the conceptual basis by pediatric intensivists in Canada. Archives of Pediatrics and Adolescent Medicine, Chicago, v. 160, n. 7, p. 747-751, jul. 2006.

JOYNT, R. J. A new look at death. Journal of the American Medical Association, Chicago, v. 25, n. 5, p. 680 - 682. 1984.

LEITE, R. C. C. Transplantes de órgãos e tecidos e os direitos da personalidade. São Paulo: Juarez de Oliveira, 2000. 282 p.

MACEDO, L. C.; OLIVEIRA, J. A. Perfil epidemiológico dos potencias e efetivos doadores de órgãos de Campo Mourão - PR. SaBios-Revista de Saúde e Biologia, v. 8, n. 3, p. 40-48, ago/dez. 2013.

MANGINI, S.; ALVES, B. R.; SILVESTRE, O. M.; PIRES, P. V.; PIRES, L. J. T.; CURIATI, M. N. C.; BACAL, F. Transplante cardíaco: revisão. Einstein, São Paulo, v. 13 , n. 2, p. $310-318$, abr/jun. 2015.

MARINHO, A. Um estudo sobre as filas para transplantes no Sistema Único de Saúde brasileiro. Caderno de Saúde Pública, Rio de Janeiro, v. 22, n. 10, out. 2006.

MARTÍN-ESCOBAR, E. Importance of intensive care professionals for organ donation and transplantation. Revista Brasileira de Terapia Intensiva, Rio de Janeiro, v. 24, n. 4, p. 316-317. 2012.

MARTINELLI, P. Há 50 anos, o primeiro transplante. Correio Popular, 2013. Disponível em: <http://correio.rac.com.br/_conteudo/2013/10/capa/projetos_correio/cenario_xxi/1087 22-ha-50-anos-o-primeiro-transplante.html>. Acesso em: 20 jul. 2017. 
MENDES, K. D. S.; ROZA, B. A.; BARBOSA, S. F. F.; SCHIRMER, J.; GALVÃO, C. $M$. Transplante de órgãos e tecidos: responsabilidades do enfermeiro. Texto \& Contexto Enfermagem, Florianópolis, v. 21, n. 4, p. 945-953, out/dez. 2012.

MINISTÉRIO DA SAÚDE (MS). Portaria MS no 2600, de 21 de outubro de 2009. Aprova o regulamento técnico do sistema nacional de transplantes. Diário Oficial da União, Brasília, 2009.

MORAES, E. L.; SILVA, L. B. B.; MORAES, T. C.; PAIXÃO, N. C. S.; IZUMI, N. M. S.; GUARINO, A. J. O perfil de potenciais doadores de órgãos e tecidos. Revista Latino-Americana de Enfermagem, Ribeirão Preto, v. 17, n. 5, p. 120 - 124, set/out. 2009.

MORAES, M. W.; GALLANI, M. C. B. J.; MENEGHIN, P. Crenças que influenciam adolescentes na doação de órgãos. Revista da Escola de Enfermagem da USP, São Paulo, v. 40, n. 4, p. 484-492. 2006.

MORAIS, T. R.; MORAIS, M. R. Doação de órgãos: é preciso educar para avançar. Saúde em Debate, Rio de Janeiro, v. 36, n. 95, p. 633-639, out/dez. 2012.

MOURA, L. C.; SILVA, V. S. Manual do núcleo de captação de órgãos: iniciando uma Comissão Intra-Hospitalar de Doação de Órgãos e Tecidos para Transplantes: CIHDOTT. Hospital Albert Einstein, São Paulo: Minha Editora, 2014. $154 \mathrm{p}$.

OLIVEIRA, J. G. R.; OLIVEIRA, M. R. B; VIEIRA, L. J. E. S.; SILVA JUNIOR, G. B. Aumento do número de mortes violentas e transplante de órgãos no Brasil: há um paralelo? Jornal Brasileiro de Nefrologia, São Paulo, v. 38, n. 3, p. 383-384. 2016.

PARANÁ. Secretaria de Estado da Saúde. Superintendência de Gestão de Sistemas de Saúde. Manual para notificação, diagnóstico de morte encefálica e manutenção do potencial doador de órgãos e tecidos. Curitiba: Central Estadual de Transplantes, 2014. $40 \mathrm{p}$.

PEREIRA, W. A; FERNANDES, R. C; SOLER, W. V. Diretrizes básicas para a captação de múltiplos órgãos da Associação Brasileira de Transplante de Órgãos. São Paulo: ABTO, 2009. 144 p.

PICINI, M.; GONÇALVES, J. R. R.; BRINGHENTI, T.; FORLIN, E. Avaliação de crianças com suspeita de maus-tratos físicos: um estudo de $\mathbf{5 0 0}$ casos. Revista Brasileira de Ortopedia, Rio de Janeiro, v. 52, n. 3, p. 284 - 290. 2017.

REQUIÃO-MOURA, L. R.; DURÃO JUNIOR, M. S.; MATOS, A. C. C.; PACHECHOSILVA, A. Lesão de isquemia e reperfusão no transplante renal: paradigmas hemodinâmico e imunológico. Einstein, São Paulo, v. 13, n. 1, p. 129-135, jan/mar. 2015. 
RODRIGUES, M. G1 - Distrito Federal: GDF publica decreto que reformula Saúde e cria sete superintendências. 2016. Disponível em: <http://g1.globo.com/distrito-federal/noticia/2016/01/gdf-publica-decreto-quereformula-saude-e-cria-sete-superintendencias.html>. Acesso em 20 jul 2017.

RODRIGUES, T. B.; CHAGAS, M. I. O.; BRITO, M. C. C.; SALES, D. S.; SILVA, R. C. C.; SOUZA, A. M. A. Perfil de potenciais doadores de órgãos em hospital de referência. Revista Rene, Fortaleza, v. 14, n. 4, p. 713-719. 2013.

ROZA, B. A; ODIERNA, M. T. A. S.; GLEZER, M.; SÁ, J. R. Captação de órgãos para transplantes, 2006. Disponível em: <http://www.abto.org.br/abtov03/Upload/file/Biblioteca_Teses/Textos/CaptacaodeOrg aosLivroEliasKnobellBartira.pdf>. Acesso em: 28 jul. 2017.

SALLUM, A. M. C.; ROSSATO, L. M.; SILVA, S. F. Morte encefálica em criança: subsídios para a prática clínica. Revista Brasileira de Enfermagem, Brasília, v. 64, n. 3, p. 600 - 604, mai/jun. 2011.

SIEBELINK, M. J.; ALBERS, M. J.; ROODBOL, P. F.; VAN DE WIEL, H. B. Children as donors: a national study to assess procurement of organs and tissues in pediatric intensive care unit. Transplant International, England, v. 25, n. 12, p. 1268-1274, dez. 2012a.

SIEBELINK, M. J.; ALBERS, M. J.; ROODBOL, P. F.; VAN DE WIEL, H. B. Key factors in paediatric organ and tissue donation. Transplant International, England, v. 25, n. 3, p. 265-271, mar. 2012b.

SILVA, E.; CARVALHO, J. R.; WOHLGEMUTH, F. B.; WESTPHAL, M. G. B.; BATISTA, L. N. Avaliação das causas de não efetivação de doações de múltiplos órgãos e tecidos na Central de Notificação, Captação e Distribuição de Órgãos de Santa Catarina - CNCDO -SC. Arquivos Catarinenses de Medicina, Florianópolis, v. 32, n. 1. 2002.

SOUZA, B. S. J; LIRA, G. G.; MOLA, R. Notificação da morte encefálica em ambiente hospitalar. Revista Rene, Fortaleza, v. 16, n. 2, p. 194 - 200, mar/abr. 2015.

WATSON, C. J. E.; DARK, J. H. Organ transplantation: historical perspective and current practice. British Journal of Anaesthesia, Oxford, v. 108, n. 1 (supplement), p. 29 - 42, jan. 2012.

WORKMAN, J. K.; MYRICK, C. W.; MEYERS, R. L.; BRATTON, S. L.; NAKAGAWA, T. A. Pediatric Organ Donation and Transplantation. Pediatrics, v. 131, n. 6, p. 1723-1730, jun. 2013. 


\section{APÊNDICE A - Ficha de Coleta de Dados}

\section{FICHA DE COLETA DE DADOS}

- Ano de internação:

4 - 2013

$3-2014$

$2-2015$

$1-2016$

- Idade:

$1-R N$

2 - Lactente ( 1 m a 2 anos)

3 - Pré-escolar (2 a 4 anos)

4 - Escolar (5 a 10 anos)

5 - Adolescente (11 a 18 anos)

- Sexo:

1 - Masculino

2 - Feminino

- Cor:

1 - Amarela

2 - Branca

3 - Preta

4 - Parda

5 - Não informado

- Motivos da internação:

1 - Enforcamento

2 - Atropelamento/acidente

automobilístico

3 - Hidrocefalia

4 - PAF (perfuração por arma de fogo)

5 - Tumor cerebral

6 - Cardiopatia

7 - Insuficiência respiratória

8 - Outros (especificar)

- Maus tratos:

1 - sim

2 - não

- Causas da morte encefálica:

1 - Herniação

2 - Hemorragia de SNC (sistema nervoso central)
3 - Isquemia de SNC

4 - Edema Cerebral ou Brain Swelling

5 - Outros (especificar)

- Notificação:

1 - Busca ativa pela CNCDO

2 - Notificação pela equipe do hospital

3 - Não informado

- Procedência (local do primeiro atendimento).

- Hospital em que se procedeu e se encerrou o protocolo de morte encefálica.

- Doação de órgãos:

1 - Sim

$2-N \tilde{a} o$

- Se a resposta da questão anterior for não, motivo da não doação:

1 - Doenças infectocontagiosas

transmissíveis por meio de doação de órgãos.

2 - Parada cardiorrespiratória antes do encerramento do protocolo.

3 - Não autorização dos familiares.

4 - Neoplasias Malignas.

5 - Outros (especificar)

- Órgãos mais utilizados para doação.

1 - Rim

2 - Fígado

3 - Pulmão

4 - Coração

5 - Córneas

- Hospital em que os órgãos foram retirados. 


\title{
APÊNDICE B - Dispensa de Termo de Consentimento Livre e Esclarecido
}

\author{
Brasília, 08 de dezembro de 2016.
}

Prezado relator(a) do Comitê de Ética em Pesquisa do Centro Universitário de Brasilia (UniCEUB),

Eu, Andréa Lopes Ramires Kairala, residente a SMPW quadra 16, conj 3, lote 8, Park Way, casa F, CEP - 71743603, telefone: 61992394014 , pesquisadora/orientadora responsável pelo projeto titulado "Análise do perfil dos potenciais doadores de órgăos pediátricos no Distrito Federal, de 2011 a 2015", venho, por meio deste, pedir que se reavalie a liberação do Termo de Consentimento Livre e Esclarecido.

Tendo em vista que o projeto de pesquisa mencionado, a ser desenvolvido no Hospital de Base do Distrito Federal, no período de abril a maio de 2017, será um estudo quantitativo, documental, descritivo e retrospectivo, que empregará apenas informaçōes de prontuários médicos, sistemas de informaçăo institucionais e/ou demais fontes de dados e informaçōes clínicas disponiveis na instituição sem previsão de utilização de material biológico.

Esse é um estudo não intervencionista (sem intervençōes clínicas), sendo o risco maior a quebra de privacidade em que envolve a manipulaçăo de informação pessoal do paciente, que torna-se minimo, por existir o compromisso por parte dos pesquisadores de manipulaçăo cuidadosa desses dados.

Como instrumento de coleta será utilizado uma ficha, com as seguintes variáveis: ano de internaçāo, idade, sexo, cor, motivos da internação, presença ou não de maus tratos, causa da morte encefálica, doador de órgăos efetivo ou năo-efetivo, causas de não efetivação da doaçăo e quais os órgãos mais utilizados para doação.

Em todas as pesquisas, faz-se necessário o TCLE (termo de consentimento livre e esclarecido), de acordo com a Resolução 466/12:

"IV - O respeito devido à dignidade humana exige que toda pesquisa se processe com consentimento livre e esclarecido dos participantes, individuos ou grupos que, por si e/ou por seus representantes legais, manifestem a sua anuência à participação na pesquisa. Entende-se por Processo de Consentimento Livre e Esclarecido todas as etapas a serem necessariamente observadas para que o convidado a participar de uma pesquisa possa se manifestar, de forma autônoma, consciente, livre e esclarecida"

Entretanto, a resolução reconhece algumas situaçōes especiais (Res. CNS 466/12 em seu capítulo IV.8) em que o TCLE pode ser dispensado:

"IV.8 - Nos casos em que seja inviável a obtenção do Termo de Consentimento Livre e Esclarecido ou que esta obtençăo signifique riscos substanciais à privacidade e confidencialidade dos dados do participante ou aos vínculos de confiança entre pesquisador e pesquisado, a dispensa do TCLE deve ser justificadamente solicitada pelo pesquisador responsável ao Sistema CEP/CONEP, para apreciação, sem prejuizo do posterior processo de esclarecimento."

O projeto foi avaliado pelo CEP e no parecer consta que "considerando que a pesquisa envolve análise de prontuário e as informações constantes de tal documento se referem a paciente pediátrico especifico, tão somente os responsáveis legais por tais pacientes podem consentir com o acesso ao prontuário. Dessa forma, não se verifica amparo legal para nāo se exigir a apresentaçăo do Termo de Consentimento Livre e Esclarecido." 
Existem alguns pontos, no entanto, que dificultam a obtençăo do TCLE em nossa pesquisa:

1) O Hospital de Base do Distrito Federal (HBDF) atende toda a populaçāo do DF, entorno e estados circunvizinhos para procedimentos de alta complexidade. É um hospital terciário, de referência para todos os estados do Centro-Oeste e ainda alguns estados do Nordeste (como Bahia), o que significa que uma grande parte das pessoas que recebem atendimento no hospital reside em municipios fora do Distrito Federal. Os pacientes a serem estudados nesta pesquisa receberam atendimento de alta complexidade, na Unidade de Terapia Intensiva, resultando sempre em morte encefálica (com a doaçăo de órgăos tendo sido realizada ou não). Dessa forma, a probabilidade dos familiares dos pacientes a serem estudados morarem em municipios fora do DF é alta. Logo, será muito difícil encontrar uma grande parte dos familiares e obter seu consentimento livre e esclarecido para a pesquisa.

2) Ademais, a pesquisa é retrospectiva, de 2011 a 2015, pode ser que muitos dos contatos das famílias dos pacientes, que foram atendidos já não sejam os mesmos. Todos esses fatores podem dificultar imensamente o contato e o encontro com os familiares da pesquisa, inviabilizando a obtenção de seus consentimentos livres e esclarecidos, tornando a amostra da pesquisa muito pequena e comprometendo assim sua relevância.

3) Estudos ${ }^{123}$ apontam que o processo de doação de órgãos tem, em geral, uma repercussăo boa na vida dos familiares, e apesar da dor, costuma ser uma experiência positiva, uma vez que pode confortar, dar satisfação e até ser uma honra, pois significa o bem para outras pessoas. No entanto, quando se trata da morte de um filho, principalmente de uma criança, seu enfrentamento é demasiadamente sofrido, de dificil assimilação pelos pais e, quando se apresenta a possibilidade de que seus órgăos sejam doados, o sofrimento pode ser ainda maior. Em alguns casos, pode ser uma experiência tăo terrivel, que eles podem jamais voltar a doar; o evento, muitas vezes, é encarado como uma violência ao corpo daquele que se ama, contribuindo, assim, para aumentar o sofrimento dos que terão que tomar tal decisão.

Independente da causa da tragédia que resultou na morte encefálica da criança, a familia encontra-se preocupada, amedrontada e exausta de tanto sofrimento pelo risco de vida da criança e perplexa com a surpresa do estado crítico anunciado pela equipe. A construçăo de uma nova realidade, sem a criança, năo é uma tarefa simples e pode levar tempo. Não se sabe a condição psicológica de cada familiar atualmente, pois cada um terá seu tempo de superação da perda. Lidar com a morte consiste em uma questăo dificil e muito pior para familias cuja pessoa que tem a vida interrompida é uma criança. Acredito, dessa forma, que a obtenção do TCLE possa vir a causar mais dano às familias dos pacientes, expondo-os novamente à dor da perda do seu ente querido,

1) BITTENCOURT, A. L. P.; QUINTANA, A. M.; VELHO, M. T. A. C. A perda do fillho: luto e doaçăo de órgãos. Estudos de Psicologia, Campinas, v. 28, n. 4, p. $435-442$, out/dez. 2011.

2) BOUSSO, R. S. O processo de decisăo familiar na doaçăo de órgãos do filho: uma teoria substantiva. Texto Cantexto Enfermagem, Florianópolis, v. 17, n. 1, p. 45-54, jan/mar. 2008.

3) QUINTANA, A. M.; ARPINI, D. M. Doaçăo de órgăos: possiveis elementos de resistência e aceitaçăo. Bọletim de Psicologie Săo Paulo, v. 59, n. 130, p. 91-102, 2009. 
fazendo-os reviver todo o sofrimento passado, sem o devido suporte social para o enfrentamento da situaçăo.

Reitero que todos os dados serăo manejados e analisados de forma anônima, sem identificação nominal dos participantes da pesquisa; daremos um número para cada participante, sem a utilização de seus nomes, apenas para melhor organizaçăo dos dados. Além disso, os resultados do estudo serāo apresentados de forma agregada, de forma geral, năo permitindo a identificaçăo dos participantes. Protegeremos a privacidade de cada participante da pesquisa e manteremos a confidencialidade da mesma.

O investigador principal e demais colaboradores envolvidos no presente estudo se comprometem, individual e coletivamente, a utilizar os dados provenientes deste, apenas para os fins descritos e a cumprir todas as diretrizes e normas regulamentadoras descritas na Res. CNS $\mathrm{N}^{\circ} 466 / 12$, e suas complementares, no que diz respeito ao sigilo e confidencialidade dos dados coletados.

Referências

BITTENCOURT, A. L. P.; QUINTANA, A. M.; VELHO, M. T. A. C. A perda do filho: luto e doação de órgãos. Estudos de Psicologia, Campinas, v. 28, n. 4, p. 435 - 442, out/dez. 2011.

BOUSSO, R. S. O processo de decisăo familiar na doação de órgãos do filho: uma teoria substantiva. Texto Contexto Enfermagem, Florianópolis, v. 17, n. 1, p. 45-54, jan/mar. 2008.

QUINTANA, A. M.; ARPINI, D. M. Doação de órgãos: possiveis elementos de resistência e aceitação. Boletim de Psicologia, São Paulo, v. 59, n. 130, p. 91-102, 2009.
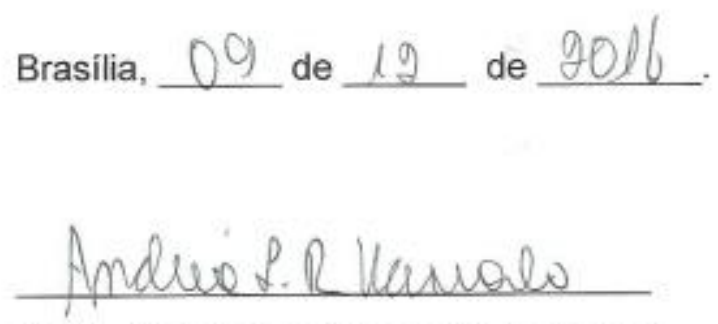

Assinatura do pesquisador responsável. 


\section{ANEXO A - Protocolo de Morte Encefálica, de acordo com o CFM}

HOSPITAL:

TERMO DE DECLARAÇÃO DE MORTE ENCEFÁLICA

(Res. CFM n'1.480 de 08/08/97)

NOME:

PAl:

MÄE:

IDADE: ANOS

F
MESES DIAS

DATA DE NASCIMENTO

SEXO: M RAÇA:A B N Registro Hospitalar:

A. CAUSA DO COMA:

A.1 - Causa do Coma:

A.2. Causas do coma que devem ser excluidas durante o exame
a) Hipotermia
( )SIM
( ) NÄO
b) Uso de drogas depressoras do sistema nervoso central
( )SIM
( ) NÃO

Se a resposta for sim a qualquer um dos itens, interrompe-se o protocolo

B. EXAME NEUROLÓGICO - Atenção: verificar o intervalo mínimo exigivel entre as avaliações clínicas, constantes da tabela abaixo:

\begin{tabular}{|l|l|}
\hline \multicolumn{1}{|c|}{ IDADE } & \multicolumn{1}{|c|}{ INTERVALO } \\
\hline 7 dias a 2 meses incompletos & 48 horas \\
\hline 2 meses a 1 ano incompleto & 24 horas \\
\hline 1 ano a 2 anos incompletos & 12 horas \\
\hline Acima de 2 anos & 06 horas \\
\hline
\end{tabular}

(Ao efetuar o exame, assinalar uma das duas opções SIM/NÃO. obrigatoriamente, para todos os itens abaixo)

Elementos do exame neurológico

\section{Coma apreceptivo}

Pupilas fixas e arreativas

Ausência de reflexo córneo-palpebral

Ausência de reflexos oculocefálicos

Ausência de respostas às provas calóricas

Ausência de reflexo de tosse

Apnéia

$$
1^{\circ} \text { exame } 22^{\circ} \text { exame }
$$

\begin{tabular}{|c|c|}
\hline 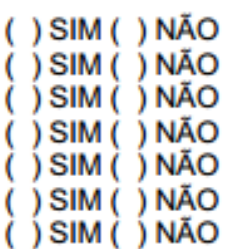 & $\begin{array}{l}\text { ( ) } \operatorname{SIM} \text { ( ) NÄO } \\
\text { () } \operatorname{SIM} \text { ( ) NÄO } \\
\text { ( ) } \operatorname{SIM} \text { ( ) NÄO } \\
\text { ( ) } \operatorname{SIM} \text { ( ) NÄO } \\
\text { () } \operatorname{SIM} \text { ( ) NÄO } \\
\text { () } \operatorname{SIM} \text { ( ) NÄO } \\
\text { () } \operatorname{SIM} \text { ( ) NÄO }\end{array}$ \\
\hline
\end{tabular}

C. ASSINATURAS DOS EXAMES CLÍNICOS - (Os exames devem ser realizados por profissionais diferentes, que não poderăo ser integrantes da equipe de remoçăo e transplante.
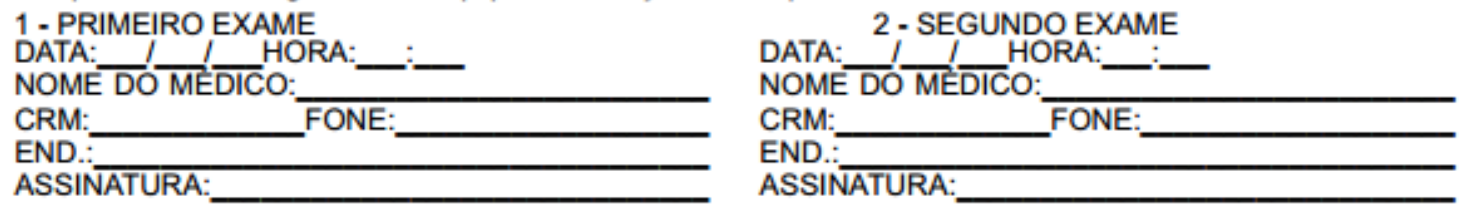

D. EXAME COMPLEMENTAR - Indicar o exame realizado e anexar laudo com identificação do médico responsável.

\begin{tabular}{|l|l|l|l|l|}
\hline $\begin{array}{l}\text { 1.Angiografia } \\
\text { Cerebral }\end{array}$ & $\begin{array}{l}\text { 2.Cintilografia } \\
\text { Radioisotópica }\end{array}$ & $\begin{array}{l}\text { 3. Doppler } \\
\text { Transcraniano }\end{array}$ & $\begin{array}{l}\text { 4.Monitorização da } \\
\text { pressão intracraniana }\end{array}$ & $\begin{array}{l}\text { 5. Tomografia } \\
\text { computadorizada } \\
\text { com xenônio }\end{array}$ \\
\hline $\begin{array}{l}\text { 6. Tomografia } \\
\text { por emissão de } \\
\text { foton único }\end{array}$ & 7. EEG & $\begin{array}{l}\text { 8. Tomografia } \\
\text { por emissão de } \\
\text { positróns }\end{array}$ & $\begin{array}{l}\text { 9. Extração Cerebral } \\
\text { de oxigênio }\end{array}$ & 10. outros (citar) \\
\hline
\end{tabular}


ANEXO B - Parecer do Comitê de Ética do UniCEUB

\section{CENTRO UNIVERSITÁRIO DE BRASÍLIA - UNICEUB}

\section{PARECER CONSUBSTANCIADO DO CEP}

\section{DADOS DO PROJETO DE PESQUISA}

Título da Pesquisa: ANÁLISE DO PERFIL DOS POTENCIAIS DOADORES DE ÓRGÃOS PEDIÁTRICOS NO DISTRITO FEDERAL, DE 2011 A 2015.

Pesquisador: Andréa Lopes Ramires Kairala

Área Temática:

Versão: 2

CAAE: 61591916.6 .0000 .0023

Instituição Proponente: Centro Universitário de Brasília - UNICEUB

Patrocinador Principal: Financiamento Próprio

\section{DADOS DO PARECER}

Número do Parecer: 1.882 .072

\section{Apresentação do Projeto:}

A presente pesquisa objetiva realizar a coleta de dados epidemiológicos de potenciais doadores de órgãos pediátricos, que sofreram morte encefálica, de 0 a 18 anos, no Distrito Federal, dos últimos 5 anos, a fim de identificar as principais causas da não captação de órgãos. Para tanto, a pesquisa irá comparar os perfis dos potenciais doadores pediátricos efetivos e não efetivos, analisar a causa de morte encefálica de cada um dos pacientes e o desfecho do caso (doação ou não doação). Ainda, a investigação tem como escopo a proposta de educação e de conscientização da população sobre a doação de órgãos para que o número de doações aumente.

Trata-se de estudo quantitativo, documental, descritivo e retrospectivo, realizado por meio de coleta e análise de dados encontrados nos protocolos finalizados de morte encefálica (manuais e eletrônicos) da Central de Notificação, Captação e Distribuição de Órgãos do Hospital de Base do Distrito Federal, referentes aos potenciais doadores pediátricos de órgãos, no período entre 2011-2015.

Assim, a pesquisa envolve a análise dos prontuários de todos os pacientes pediátricos, de 0 a 18 anos, que eram potenciais doadores de órgãos e os que doaram, contidos na base de dados da Captação de Órgãos do Hospital de Base do Distrito Federal.

A quantidade da amostra dependerá da base de dados do Hospital de Base do Distrito Federal.

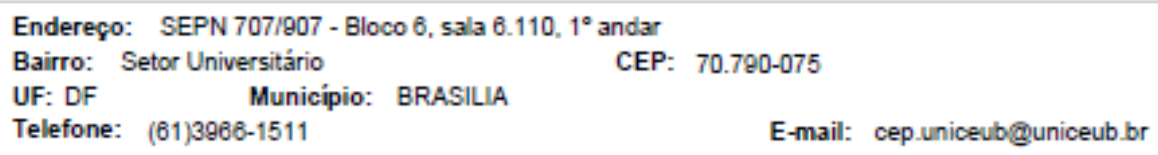




\section{CENTRO UNIVERSITÁRIO DE BRASÍLIA - UNICEUB}

Contnuaçăo do Parecer: 1.882.072

No que tange ao critério de inclusão, o pesquisa informa que serão inclusos os pacientes pediátricos, de 0 a 18 anos, que tiveram comprovação de morte encefálica, no Distrito Federal, no período de janeiro de 2011 a dezembro de 2015.

Quanto ao critério de exclusão, enuncia que serão excluídos os que envolverem a doação de órgãos intervivos.

\section{Objetivo da Pesquisa:}

O objetivo geral da pesquisa consiste na coleta dos dados epidemiológicos dos potenciais doadores de órgãos pediátricos, que sofreram morte encefálica, de 0 a 18 anos, no Distrito Federal, dos últimos 5 anos, buscando demonstrar as principais causas da não captação de órgãos.

Os objetivos secundários são os seguintes: a) verificar o perfil epidemiológico de todos os potenciais doadores de órgãos pediátricos, que sofreram morte encefálica, no Distrito Federal, de 2011 a 2015; b) comparar os perfis dos potenciais doadores pediátricos efetivos e não efetivos, analisando a causa de morte encefálica de cada um dos pacientes e o desfecho do caso (doação ou não- doação); c)demonstrar as principais causas da não captação de órgãos dos potenciais doadores.

\section{Avaliação dos Riscos e Benefícios:}

No que tange aos riscos, o pesquisador afirma que há presença de risco mínimo, na medida em que a pesquisa envolve a manipulação de informação pessoal dos participantes.

Quanto aos beneficios, relata que a avaliação das principais causas da não captação de órgãos pode levar à proposição de medidas que possam aumentar a doação de órgãos, trazendo benefícios aos futuros pacientes pediátricos que necessitem de transplante.

\section{Comentários e Considerações sobre a Pesquisa:}

A presente pesquisa apresenta relevância acadêmica e social, na medida em que concorre para a produção de conhecimento científico sobre temática de evidente impacto social, na medida em que busca, mediante a análise de dados de pacientes pediátricos que sofreram morte encefálica, propor medidas que contribuam para o aumento das doações de órgãos. Não se verifica questão ética relevante a ser suscitada e que enseje a pendência do presente protocolo de pesquisa.

O cronograma se encontra ajustado.

o Currículo Lattes e o orçamento se apresentam adequados, do ponto de vista da ética em pesquisa.

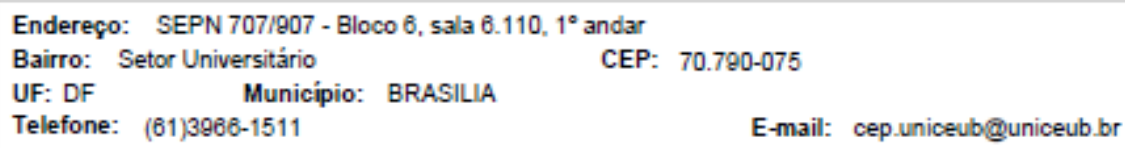




\section{CENTRO UNIVERSITÁRIO DE Q Platoforma BRASÍLIA - UNICEUB}

Contnuaçăo do Parecer: 1.882.072

No que toca ao instrumento de coleta de dados, a Ficha de Coleta de Dados, não se constata questão ética a ser suscitada no presente parecer.

Considerações sobre os Termos de apresentação obrigatória:

A Folha de Rosto se encontra devidamente preenchida.

Verifica-se a presença do Termo de Anuência de Instituição Coparticipante, subscrito pelo Diretor Geral do Hospital de Base do Distrito Federal.

Quanto ao Termo de Consentimento Livre e Esclarecido, o pesquisador solicita a sua liberação mediante Termo de Liberação específico, bem como justifica a solicitação de forma pormenorizada. Consequentemente, à luz do previsto no item IV. 8 da Resolução $n^{\circ} 466$, de 2012 , admite-se a motivação do pesquisador quanto à inviabilidade da obtenção do Termo de Consentimento Livre e Esclarecido.

Recomendações:

O CEP-UniCEUB ressalta a necessidade de desenvolvimento da pesquisa, de acordo com o protocolo avaliado e aprovado, bem como, atenção às diretrizes éticas nacionais quanto aos incisos XI.1 e XI.2 da Resolução $n^{\circ} 466 / 12 \mathrm{CNS} / \mathrm{MS}$ concernentes às responsabilidades do pesquisador no desenvolvimento do projeto:

XI.1 - A responsabilidade do pesquisador é indelegável e indeclinável e compreende os aspectos éticos e legais.

$\mathrm{XI} .2$ - Cabe ao pesquisador:

c) desenvolver o projeto conforme delineado;

d) elaborar e apresentar os relatórios parciais e final;

e) apresentar dados solicitados pelo CEP ou pela CONEP a qualquer momento;

f) manter os dados da pesquisa em arquivo, físico ou digital, sob sua guarda e responsabilidade, por um período de 5 anos após o término da pesquisa;

g) encaminhar os resultados da pesquisa para publicação, com os devidos créditos aos pesquisadores associados e ao pessoal técnico integrante do projeto; $\mathrm{e}$

h) justificar fundamentadamente, perante o CEP ou a CONEP, interrupção do projeto ou a não publicação dos resultados.

Observação: Ao final da pesquisa enviar Relatório de Finalização da Pesquisa ao CEP. $O$ envio de relatórios deverá ocorrer pela Plataforma Brasil, por meio de notificação de evento. O modelo do relatório encontra-se disponível na página do UniCEUB

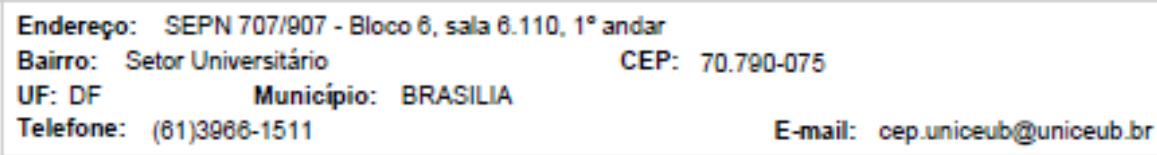




\section{CENTRO UNIVERSITÁRIO DE Q Plotoforma BRASÍLIA - UNICEUB}

Contnuaçăo do Parecer. 1.882 .072

http://www.uniceub.br/instituicao/pesquisa/ins030_pesquisacomitebio.aspx, em Relatório de Finalização e Acompanhamento de Pesquisa.

Conclusões ou Pendências e Lista de Inadequações:

A pesquisa se encontra apta a ser iniciada.

Consideraçôes Finais a critério do CEP:

Protocolo avaliado e aprovado ad referendum pelo CEP-UniCEUB, com parecer $\mathrm{N}^{\circ} 1.871 .815 / 2016$, tendo sido homologado pela coordenação em 26 de dezembro de 2016.

Este parecer foi elaborado baseado nos documentos abaixo relacionados:

\begin{tabular}{|c|c|c|c|c|}
\hline Tipo Documento & Arquivo & Postagem & Autor & Situação \\
\hline $\begin{array}{l}\text { Informações Básicas } \\
\text { do Projeto }\end{array}$ & $\begin{array}{l}\text { PB_INFORMAÇÖES_BÁSICAS_DO_P } \\
\text { ROJETO 770192.pdf }\end{array}$ & $\begin{array}{c}09 / 12 / 2016 \\
18: 10: 17\end{array}$ & & Aceito \\
\hline $\begin{array}{l}\text { TCLE / Termos de } \\
\text { Assentimento / } \\
\text { Justificativa de } \\
\text { Ausência }\end{array}$ & exposicao_motivos_tcle.pdf & $\begin{array}{c}09 / 12 / 2016 \\
18: 08: 32\end{array}$ & $\begin{array}{l}\text { Bruna Rolim Peixoto } \\
\text { da Silva }\end{array}$ & Aceito \\
\hline Outros & termo_compromisso01.pdf & $\begin{array}{c}09 / 12 / 2016 \\
18: 00: 29 \\
\end{array}$ & \begin{tabular}{|l|} 
Bruna Rolim Peixoto \\
da Silva
\end{tabular} & Aceito \\
\hline Cronograma & Cronograma.docx & $\begin{array}{c}09 / 12 / 2016 \\
17: 25: 01 \\
\end{array}$ & $\begin{array}{l}\text { Bruna Rolim Peixoto } \\
\text { da Silva }\end{array}$ & Aceito \\
\hline $\begin{array}{l}\text { Projeto Detalhado / } \\
\text { Brochura } \\
\text { Investigador }\end{array}$ & Doacao_de_orgaos.docx & $\begin{array}{c}09 / 12 / 2016 \\
17: 24: 48\end{array}$ & $\begin{array}{l}\text { Bruna Rolim Peixoto } \\
\text { da Silva }\end{array}$ & Aceito \\
\hline Outros & ficha_de_coleta_de_dados_anexo.docx & $\begin{array}{c}26 / 10 / 2016 \\
20: 31: 58 \\
\end{array}$ & $\begin{array}{l}\text { Bruna Rolim Peixoto } \\
\text { da Silva }\end{array}$ & Aceito \\
\hline Outros & anuencia.pdf & $\begin{array}{c}26 / 10 / 2016 \\
20: 30: 11 \\
\end{array}$ & $\begin{array}{l}\text { Bruna Rolim Peixoto } \\
\text { da Silva }\end{array}$ & Aceito \\
\hline Orçamento & orcamento_anexo.doc & $\begin{array}{c}26 / 10 / 2016 \\
20: 29: 01 \\
\end{array}$ & $\begin{array}{l}\text { Bruna Rolim Peixoto } \\
\text { da Silva } \\
\end{array}$ & Aceito \\
\hline Folha de Rosto & folha_de_rosto.pdf & $\begin{array}{c}26 / 10 / 2016 \\
20: 25: 28 \\
\end{array}$ & $\begin{array}{l}\text { Bruna Rolim Peixoto } \\
\text { da Silva } \\
\end{array}$ & Aceito \\
\hline
\end{tabular}

Situação do Parecer:

Aprovado

Necessita Apreciação da CONEP:

Não

Endereço: SEPN 707/907 - Bloco 6, sala 6.110, $1^{\circ}$ andar

Bairro: Setor Universitário CEP: $70.790-075$

UF: DF Municipio

Município: BRASILIA

Telefone: (61)3966-1511

E-mail: cep.uniceub@uniceub.br 


\section{ANEXO C - Parecer do Comitê de Ética da FEPECS/SES/DF}

FUNDAÇÃO DE ENSINO E
PESQUISA EM CIÊNCIAS DA
SAÚDE/ FEPECS/ SES/ DF

\section{PARECER CONSUBSTANCIADO DO CEP}

Elaborado pela Instituição Coparticipante

\section{DADOS DO PROJETO DE PESQUISA}

Título da Pesquisa: ANÁLISE DO PERFIL DOS POTENCIAIS DOADORES DE ÓRGÃOS PEDIÁTRICOS NO DISTRITO FEDERAL, DE 2011 A 2015.

Pesquisador: Andréa Lopes Ramires Kairala

Área Temática:

Versão: 1

CAAE: 61591916.6 .3001 .5553

Instituição Proponente: Centro Universitário de Brasília - UNICEUB

Patrocinador Principal: Financiamento Próprio

\section{DADOS DO PARECER}

Número do Parecer: 1.910 .132

\section{Apresentação do Projeto:}

Projeto de iniciação científica com financiamento próprio, proposto pelo UNICEUB, tendo o HBDF como instituição Co-participante e que pretende traçar o perfil dos potenciais doadores de órgãos infantis no DF no período de 2011 a 2015.

Objetivo da Pesquisa:

O principal objetivo da pesquisa é " coletar os dados epidemiológicos dos potenciais doadores de órgãos pediátricos, que sofreram morte encefálica, de 0 a 18 anos, no Distrito Federal, dos últimos 5 anos, buscando demonstrar as principais causas da não-captação de órgãos".

Os objetivos secundários são:

1.Verificar o perfil epidemiológico de todos os potenciais doadores de órgãos pediátricos, que sofreram morte encefálica, no Distrito Federal, de 2011 a 2015.

2.Comparar os perfis dos potenciais doadores pediátricos efetivos e não-efetivos, analisando a causa de morte encefálica de cada um dos pacientes e o desfecho do caso (doação ou não-doação).

3.Demonstrar as principais causas da não-captação de órgãos dos potenciais doadores.

4.Analisar o número total de doadores pediátricos efetivos e não-efetivos, assim como o número total de transplantes realizados, visando a proposta de educação e conscientização da população

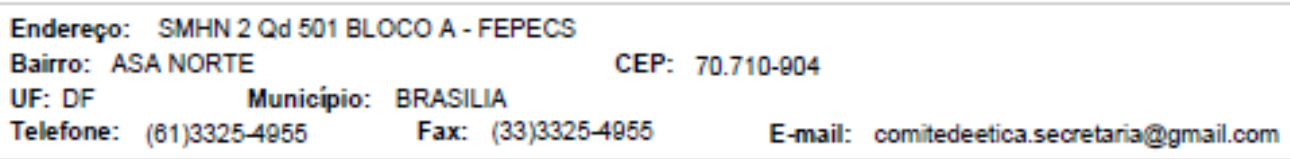




\section{FUNDAÇÃO DE ENSINO E PESQUISA EM CIÊNCIAS DA SAÚDE/ FEPECS/ SES/ DF

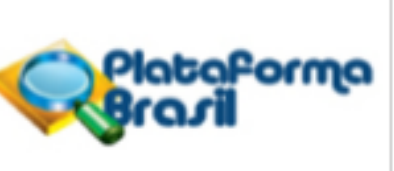

Contnuaçăo do Parecer. 1.910.132

sobre a doação de órgãos, para que assim o número de doações aumente.

\section{Avaliação dos Riscos e Beneficios:}

Conforme apresentado pelo pesquisador:

*Riscos:

Não há riscos previsiveis para os sujeitos envolvidos na pesquisa.

*Benefícios:

A avaliação das principais causas da não-captação de órgãos pode levar à proposição de medidas que possam aumentar a doação de órgãos, assim trazendo benefícios aos futuros pacientes pediátricos que necessitem de transplante.

Comentários e Consideraçōes sobre a Pesquisa:

A metodologia para realização dessa pesquisa irá considerar os protocolos finalizados de morte encefálica da captação de órgãos do HBDF.

Os critérios de inclusão e exclusão estão claramente definidos, sendo excluídos dessa pesquisas os "doadores de órgãos in vivo".

Considerações sobre os Termos de apresentação obrigatória:

1. Folha de rosto: Assinada pelo Coordenador do Curso de Medicina do UNICEUB

2. TCLE: Apresentado Requerimento de dispensa do TCLE pela natureza da pesquisa. apresenta carta que motiva essa dispensa com justificativas procedentes.

3. Termo de anuência: Assinado pelo Diretor, pela chefe da Unidade de UTI Pediátrica e pelo chefe da Central Captação de órgãos do HBDF.

4. Cronograma: Foi apresentado novo cronograma com datas ajustadas e compativeis com a deliberação do CEP-FEPECS

Recomendações:

1. Reapresentar o pedido de dispensa de TCLE, modificando a seguinte parte do texto "tendo em vista que o projeto de pesquisa..., a ser desenvolvido no HBDF, no período de outubro a março..". Sugestão: "tendo em vista que...., a ser desenvolvido no HBDF, após a aprovação pelo Comitê de Ética em PesquisaFEPECS". Dessa forma, o pesquisador assegura o conhecimento de fato do que está normatizado na Resolução CNS/MS n 466/2012 (mesmo que se trate de um documento de dispensa do mesmo)

2. Os riscos devem ser devidamente descritos conforme a resolução CNS-MS nº 466 de 2012 " A

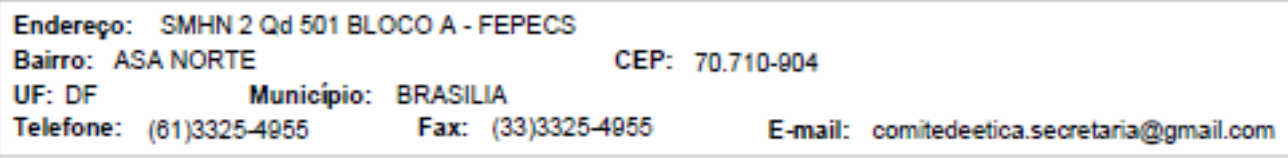




\section{FUNDAÇÃO DE ENSINO E PESQUISA EM CIÊNCIAS DA SAÚDE/ FEPECS/ SES/ DF}

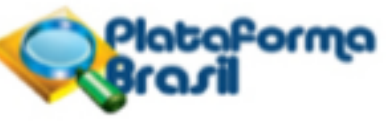

Contnuaçăo do Parecer: 1.910 .132

eticidade da pesquisa implica em (...) ponderação entre riscos e benefícios, tanto CONHECIDOS como POTENCIAIS". O fato de não haver intervenção terapêutica, não implica na não existência de riscos. Sendo assim, os mesmo devem ser descritos no projeto apresentado à luz da resolução CNS-MS n 466 de 2012. Atentar que esses riscos foram descritos em alguma partes dos arquivos apresentados, porém não foram expressos de forma adequada no campo referente a riscos na plataforma (Ex:atenção a confidenciabilidade dos dados e a privacidade das informações, entre outras). Sendo assim, não se deve preencher esse campo conforme foi apresentado na plataforma pelo pesquisador, como "Não há riscos previsíveis para os sujeitos envolvidos na pesquisa".

Conclusões ou Pendências e Lista de Inadequações:

Apresentou respostas as pendências apontadas (descrição adequada dos riscos da pesquisa)

Consideraçôes Finais a critério do CEP:

Pesquisadora encaminhou respostas as pendências aceitas pelo colegiado.

Consideraçôes Finais a critério do CEP:

Pesquisadora encaminhou respostas as pendências aceitas pelo colegiado.

Este parecer foi elaborado baseado nos documentos abaixo relacionados:

\begin{tabular}{|c|c|c|c|c|}
\hline Tipo Documento & Arquivo & Postagem & Autor & Situação \\
\hline $\begin{array}{l}\text { Informações Básicas } \\
\text { do Projeto }\end{array}$ & \begin{tabular}{|l} 
PB_INFORMAÇÖES_BÁSICAS_DO_P \\
ROJETO_770192.pdf
\end{tabular} & $\begin{array}{c}09 / 12 / 2016 \\
18: 10: 17\end{array}$ & & Aceito \\
\hline $\begin{array}{l}\text { TCLE / Termos de } \\
\text { Assentimento / } \\
\text { Justificativa de } \\
\text { Ausência }\end{array}$ & exposicao_motivos_tcle.pdf & $\begin{array}{c}09 / 12 / 2016 \\
18: 08: 32\end{array}$ & $\begin{array}{l}\text { Bruna Rolim Peixoto } \\
\text { da Silva }\end{array}$ & Aceito \\
\hline Outros & termo_compromisso01.pdf & $\begin{array}{c}\text { 09/12/2016 } \\
18: 00: 29\end{array}$ & $\begin{array}{l}\text { Bruna Rolim Peixoto } \\
\text { da Silva }\end{array}$ & Aceito \\
\hline Cronograma & Cronograma.docx & $\begin{array}{c}09 / 12 / 2016 \\
17: 25: 01\end{array}$ & $\begin{array}{l}\text { Bruna Rolim Peixoto } \\
\text { da Silva }\end{array}$ & Aceito \\
\hline $\begin{array}{l}\text { Projeto Detalhado / } \\
\text { Brochura } \\
\text { Investigador }\end{array}$ & Doacao_de_orgaos.docx & $\begin{array}{c}09 / 12 / 2016 \\
17: 24: 48\end{array}$ & $\begin{array}{l}\text { Bruna Rolim Peixoto } \\
\text { da Silva }\end{array}$ & Aceito \\
\hline $\begin{array}{l}\text { Informações Básicas } \\
\text { do Projeto }\end{array}$ & $\begin{array}{l}\text { PB_INFORMAÇŐES_BÁSICAS_DO_P } \\
\text { ROJETO_770192.pdf }\end{array}$ & $\begin{array}{c}26 / 10 / 2016 \\
20: 35: 04\end{array}$ & & Aceito \\
\hline Cronograma & Cronograma.docx & $\begin{array}{c}26 / 10 / 2016 \\
20: 32: 37\end{array}$ & $\begin{array}{l}\text { Bruna Rolim Peixoto } \\
\text { da Silva }\end{array}$ & Aceito \\
\hline Outros & ficha_de_coleta_de_dados_anexo.docx & $\begin{array}{c}26 / 10 / 2016 \\
20: 31: 58 \\
\end{array}$ & $\begin{array}{l}\text { Bruna Rolim Peixoto } \\
\text { da Silva }\end{array}$ & Aceito \\
\hline Outros & anuencia.pdf & $\begin{array}{c}26 / 10 / 2016 \\
20: 30: 11\end{array}$ & $\begin{array}{l}\text { Bruna Rolim Peixoto } \\
\text { da Silva }\end{array}$ & Aceito \\
\hline Orçamento & orcamento_anexo.doc & $26 / 10 / 2016$ & Bruna Rolim & Aceito \\
\hline
\end{tabular}

Endereço: SMHN 2 Qd 501 BLOCO A - FEPECS

Bairro: ASA NORTE

UF: DF Municipio: BRASILIA

CEP: $70.710-904$

Fax: $(33) 3325-4955$

E-mail: comitedeetica.secretaria@gmail.com 


\section{FUNDAÇÃO DE ENSINO E PESQUISA EM CIÊNCIAS DA SAÚDE/ FEPECS/ SES/ DF}

Contnuaçăo do Parecer. 1.910.132

\begin{tabular}{|c|c|c|c|c|}
\hline Orçamento & orcamento_anexo.doc & $20: 29: 01$ & Peixoto da Silva & Aceito \\
\hline $\begin{array}{l}\text { Projeto Detalhado / } \\
\text { Brochura } \\
\text { Investigador }\end{array}$ & Doacao_de_orgaos.docx & $\begin{array}{c}26 / 10 / 2016 \\
20: 28: 33\end{array}$ & $\begin{array}{l}\text { Bruna Rolim Peixoto } \\
\text { da Silva }\end{array}$ & Aceito \\
\hline $\begin{array}{l}\text { TCLE / Termos de } \\
\text { Assentimento / } \\
\text { Justificativa de } \\
\text { Ausência }\end{array}$ & tcleliberacao.pdf & $\begin{array}{c}26 / 10 / 2016 \\
20: 27: 37\end{array}$ & $\begin{array}{l}\text { Bruna Rolim Peixoto } \\
\text { da Silva }\end{array}$ & Aceito \\
\hline Folha de Rosto & folha_de_rosto.pdf & $\begin{array}{c}26 / 10 / 2016 \\
20: 25: 28\end{array}$ & $\begin{array}{l}\text { Bruna Rolim Peixoto } \\
\text { da Silva }\end{array}$ & Aceito \\
\hline
\end{tabular}

Situação do Parecer:

Aprovado

Necessita Apreciação da CONEP:

Não

BRASILIA, 06 de Fevereiro de 2017

Assinado por:

Helio Bergo

(Coordenador) 